\title{
Nrf2 activation through the PI3K/GSK-3 axis protects neuronal cells from $A \beta$-mediated oxidative and metabolic damage
}

\author{
Krystal Sotolongo ${ }^{1}$, Jorge Ghiso ${ }^{1,2^{*}+}$ and Agueda Rostagno ${ }^{1 *+}$ (D)
}

\begin{abstract}
Background: Mounting evidence points to a crucial role of amyloid- $\beta$ (A $\beta$ ) in the pathophysiology of Alzheimer's disease (AD), a disorder in which brain glucose hypometabolism, downregulation of central elements of phosphorylation pathways, reduced ATP levels, and enhanced oxidative damage coexist, and sometimes precede, synaptic alterations and clinical manifestations. Since the brain has limited energy storage capacity, mitochondria play essential roles in maintaining the high levels of energy demand, but, as major consumers of oxygen, these organelles are also the most important generators of reactive oxygen species (ROS). Thus, it is not surprising that mitochondrial dysfunction is tightly linked to synaptic loss and AD pathophysiology. In spite of their relevance, the mechanistic links among ROS homeostasis, metabolic alterations, and cell bioenergetics, particularly in relation to $A \beta$, still remain elusive.
\end{abstract}

Methods: We have used classic biochemical and immunocytochemical approaches together with the evaluation of real-time changes in global energy metabolism in a Seahorse Metabolic Analyzer to provide insights into the detrimental role of oligA $\beta$ in SH-SY5Y and primary neurons testing their pharmacologic protection by small molecules.

Results: Our findings indicate that oligomeric A $\beta$ induces a dramatic increase in ROS production and severely affects neuronal metabolism and bioenergetics. Assessment of global energy metabolism in real time demonstrated A $\beta$-mediated reduction in oxygen consumption affecting basal and maximal respiration and causing decreased ATP production. Pharmacologic targeting of A $\beta$-challenged neurons with a set of small molecules of known antioxidant and cytoprotective activity prevented the metabolic/bioenergetic changes induced by the peptide, fully restoring mitochondrial function while inducing an antioxidant response that counterbalanced the ROS production. Search for a mechanistic link among the protective small molecules tested identified the transcription factor Nrf2_compromised by age and downregulated in $\mathrm{AD}$ and transgenic models - as their main target and the PI3K/GSK-3 axis as the central pathway through which the compounds elicit their $A \beta$ protective action.

Conclusions: Our study provides insights into the complex molecular mechanisms triggered by oligA $\beta$ which profoundly affect mitochondrial performance and argues for the inclusion of small molecules targeting the PI3K GSK-3 axis and Nrf2-mediated pathways as part of the current or future combinatorial therapies.

Keywords: Alzheimer's disease, Amyloid- $\beta$, Mitochondria, Methazolamide, Melatonin, Trolox, Oxidative stress, Cell metabolism and bioenergetics, Oxygen consumption, Cellular respiration

\footnotetext{
* Correspondence: jorge.ghiso@nyumc.org; agueda.rostagno@nyumc.org

†Jorge Ghiso and Agueda Rostagno contributed equally to this work.

1'Department of Pathology, New York University School of Medicine, 550 First

Avenue, New York, NY 10016, USA

Full list of author information is available at the end of the article
}

(c) The Author(s). 2020 Open Access This article is distributed under the terms of the Creative Commons Attribution 4.0 International License (http://creativecommons.org/licenses/by/4.0/), which permits unrestricted use, distribution, and reproduction in any medium, provided you give appropriate credit to the original author(s) and the source, provide a link to the Creative Commons license, and indicate if changes were made. The Creative Commons Public Domain Dedication waiver (http://creativecommons.org/publicdomain/zero/1.0/) applies to the data made available in this article, unless otherwise stated. 


\section{Background}

Alzheimer's disease (AD), the most common type of dementia, is neuropathologically characterized by the presence of hyperphosphorylated tau in intraneuronal neurofibrillary tangles and the deposition of amyloid- $\beta$ $(\mathrm{A} \beta)$ in the brain parenchyma and cerebral vasculature [1]. Although it remains unclear what primarily triggers and drives the progression of AD, strong evidence supports a pathogenic role for $\mathrm{A} \beta$ oligomeric conformations $[2,3]$. It is now considered that the transition from soluble monomeric species normally present in body fluids to the oligomeric, protofibrillar, and end-point fibrillar assemblies contributes significantly to disease pathogenesis. Intermediate oligomeric and protofibrillar forms seem to display the most potent effects in neuronal cells inducing synaptic disruption, neurotoxicity, and ultimately neurodegenerative cell death $[3,4]$.

The molecular mechanisms leading to $\mathrm{AD}$ pathophysiology are complex and not fully elucidated with mounting evidence highlighting a central role for mitochondrial dysfunction taking place at the early stages of the disease and supporting a causative role for these abnormalities in $\mathrm{AD}$ pathogenesis $[5,6]$. Previous studies from our lab as well as the work of others indicate that $A \beta$ accumulation leads to a cascade of events affecting mitochondrial function not only in neurons and glial cell populations but also in cells of the cerebral microvasculature [7-13]. In this sense, our work has described in detail the $A \beta$-elicited initiation of apoptotic pathways demonstrating induction of caspase-mediated mitochondrial pathways with changes in mitochondrial membrane potential, Bax (Bcl-2-associated $\mathrm{X}$ protein) translocation, and cytochrome c release to the cytosol, events that ultimately lead to cellular death [7-9, 14].

Mitochondria are increasingly recognized as subcellular organelles essential for generating the energy that fuels cell function while simultaneously monitoring cellular health and acting as regulators of programmed cell death. Under physiological conditions, the brain requires high metabolic energy to sustain transport systems at endothelial barriers and maintain ion gradients across membranes critical for the generation of action potentials. Based on the limited glycolytic capacity of neurons, these cells are highly dependent on mitochondriamediated aerobic oxidative phosphorylation (OXPHOS) for their energetic needs. As the main consumers of oxygen, mitochondria are also the main generators of toxic reactive oxygen species (ROS) as products of normal cellular respiration $[5,15]$. Under circumstances in which these radicals overwhelm the neuronal capacity to neutralize them, irreversible damage to cellular components occurs resulting in oxidative damage to nucleic acids, proteins, and lipids, neuronal injury, initiation of apoptotic cascades facilitating the formation of the apoptosome, and subsequent cell death [16].
The pathogenic relevance of mitochondrial function for $\mathrm{AD}$ has boosted interest in pharmacologic targeting of these organelles which is currently actively pursued as potential therapeutic strategies. Along this line, different antioxidant agents have been tested to counterbalance oxidative stress generation in in vitro paradigms, in different animal models of various neurodegenerative disorders, and for some of them in humans. Among the many molecules tested are the saffron-derived compound crocin, polyphenols like resveratrol, and vitamin E [17-21]. More recently, two specific inhibitors of cytochrome $\mathrm{c}$ release lacking additional multifunctional activity-methazolamide (MTZ) and melatonin (MEL) were identified by screening a library of compounds (NINDS Drug Screening Consortium) on isolated mitochondria [22] and proved to be neuroprotective in models of Huntington's disease and ischemic injury [22, 23]. Work from our lab has shown that MTZ rescues microvascular, glial, and neuronal cells from $A \beta-$ mediated apoptosis, restoring mitochondrial membrane potential, preventing cytochrome $\mathrm{c}$ release to the cytoplasma, precluding activation of mitochondria-associated caspase-9, and ultimately inhibiting the activation of terminal caspases and the induction of cell death mechanisms [7, 8, 24]. Additional research has also shown a protective role of MEL from $A \beta$-mediated mitochondrial alterations through the compound's antioxidant features $[25,26]$. This protective effect extends beyond MEL radical scavenging properties preserving mitochondrial membrane potential and exerting broad effects on mitochondrial activity attenuating activation of initiator caspase- 9 and the effector caspase-3/7 [22, 27-29].

The work presented herein expands current knowledge on the cellular pathways detrimentally affected by $\mathrm{A} \beta$ providing an insight into the mechanisms by which MTZ, MEL, and the vitamin E analog Trolox prevent not only the formation of oxidative radicals but also the concomitant metabolic/bioenergetic neuronal alterations. The data identify the ability of the three small molecule compounds to activate $\mathrm{Nrf2}$, a key central regulator of the antioxidant response, as a common mechanistic link responsible for their protective activity. Through a combination of real-time metabolic/bioenergetic assessments and immunocytochemical approaches together with ELISA and dot and Western blot analyses of nuclear extracts, as well as the use of specific kinase inhibitors, the manuscript clearly demonstrates that MTZ, MEL, and Trolox protective effect on $A \beta$-mediated alterations relies on the activation of the transcription factor Nrf2 through the PI3K/Akt axis. The work unveils new targets for potential pharmacologic interventions opening new routes of translational research for the future development of novel therapeutic applications. 


\section{Material and methods Materials}

Methazolamide (MTZ, N-[5-(aminosulfonyl)-3-methyl-1,3, 4-thiadiazol-2(3H)-ylidene]-acetamide), melatonin (MEL, $N$-acetyl-5-methoxy tryptamine), Trolox (6-hydroxy-2,5,7, 8-tetramethylchroman-2-carboxylic acid), and sulforaphane (SFN, 1-isothiocyanato-4-(methylsulfinyl)-butane) were procured from Sigma. The PI3K inhibitors Wortmannin and LY294002 were from Millipore-Sigma (Burlington, MA) and Cell Signaling (Danvers, MA), respectively. The GSK-3 inhibitor SB216763 was purchased from Cell Signaling.

\section{Synthetic peptides}

Synthetic homologs of A $\beta 1-42$ were synthesized using $N$ tert-butyloxycarbonyl chemistry at ERI Amyloid Laboratory (Oxford, CT). Peptides were purified by reverse-phase highperformance liquid chromatography on a Vydac C4 column (Western Analytical, Murrieta, CA), molecular masses were corroborated by matrix-assisted laser desorption ionization time-of-flight (MALDI-TOF) mass spectrometry, and concentrations were assessed by amino acid analysis, as previously reported [8]. Peptides were dissolved at a concentration of $1 \mathrm{mg} / \mathrm{ml}$ in 1,1,1,3,3,3, hexafluoro-isopropanol (HFIP; Sigma Chemical Co., St. Louis, MO) and incubated overnight a room temperature (RT), a pretreatment that breaks down $\beta$-sheet structures and disrupts hydrophobic forces leading to monodisperse amyloid subunit preparations [30]. Following lyophilization, peptides were thoroughly dissolved to 10 $\mathrm{mM}$ in dimethyl sulfoxide (DMSO, Sigma), brought up to 1 $\mathrm{mM}$ with deionized water, and further diluted in culture media to the desired concentrations indicated below, in agreement with our previously reported protocols [8, 31].

\section{Cell cultures}

Immortalized SH-SY5Y neuroblastoma cells were obtained from the American Type Culture Collection (ATCC, Manassas, VA, USA) and maintained in DMEM/F12 medium (Mediatech, Manassas, VA) with $10 \%$ fetal bovine serum and $1 \%$ penicillin/streptomycin using standard protocols from our laboratory [31]. Primary cortical neuron cultures were prepared from embryonic day 18 rat brain tissue (Sprague Dawley; Charles River, Sharon, MA), in compliance with the New York University School of Medicine Institutional Animal Care and Use Committee, as described [32]. After dissection, the cortices were incubated $15 \mathrm{~min}$ at $37^{\circ} \mathrm{C}$ in PBS/glucose/HEPES buffer (33 mM glucose/10 mM HEPES in $10 \mathrm{mM}$ phosphate-buffered saline containing $138 \mathrm{mM}$ $\mathrm{NaCl}$ and $2.7 \mathrm{mM} \mathrm{KCl}, \mathrm{pH} 7.4$ ) added of $0.25 \%$ trypsin, followed by mechanical disruption. Cells were resuspended in DMEM, seeded on poly-D-lysine-coated plates or glass coverslips depending on the subsequent experimental use; after $1 \mathrm{~h}$, the media were changed to
Neurobasal (Thermo Fisher Scientific/Invitrogen, Carlsbad, CA) containing 2\% B27, glutamine, and penicillin/ streptomycin. A one-time dose of the antimitotic drug AraC $(1 \mu \mathrm{M}$, Sigma Chemical Co., St. Louis, MO) was added after 6 days in culture to inhibit growth of dividing cells [32]. Purity of the resulting cultures was assessed by immunofluorescence (IF) evaluation of the neuronal marker neurofilament protein and astroglial contamination estimated by assessment of glial fibrillary acidic protein (GFAP), as described below. Under these experimental conditions, primary cultures consisted of > $90 \%$ neurons.

\section{Assessment of $A \beta$ oligomerization \\ Dot blot analysis}

The presence of oligomeric forms of $A \beta 42$ in the culture supernatants from A $\beta$-challenged SH-SY5Y cells treated with $\mathrm{A} \beta 42(10 \mu \mathrm{M} ; 24 \mathrm{~h})$ in the presence/absence of MTZ $(300 \mu \mathrm{M})$, MEL $(100 \mu \mathrm{M})$, or Trolox $(300 \mu \mathrm{M})$ was assessed by dot blot using rabbit polyclonal A11 antioligomer antibody (Thermo Fisher Scientific/Invitrogen) [33], as we previously described [8, 34]. Briefly, $80 \mu \mathrm{l}$ of each of the culture supernatants was loaded onto a nitrocellulose membrane assembled into a Bio-Dot Microfiltration Apparatus (Bio-Rad, Hercules, CA). As a negative control for $A \beta$ oligomer formation, the membranes were loaded with freshly solubilized HFIP-treated synthetic A 342 (800 ng). In all cases, samples were allowed to diffuse passively for $30 \mathrm{~min}$ before vacuum application and the membrane was subsequently blocked in situ for $1 \mathrm{~h}$ with $1 \%$ nonfat milk in TBST, followed by vacuum application and two washes with TBST. After removal from the dot blot apparatus and further blocking with 5\% milk in TBST [ $1 \mathrm{~h}$, room temperature (RT)], the membrane was incubated overnight with A11 antibody (1:1000) followed by HRP-conjugated anti-rabbit secondary antibody (GE Healthcare Life Sciences, Marlborough, MA; 1: 2000, $1 \mathrm{~h}$ at RT). As a loading control, a set of wells filled with either the respective cell supernatants or the freshly solubilized synthetic A $\beta 42$ was incubated with 4 G8 monoclonal anti-A $\beta$ antibody (BioLegend, San Diego, CA; 1: 1000 , overnight at $4{ }^{\circ} \mathrm{C}$ ) followed by HRP-conjugated antimouse IgG (GE Healthcare Life Sciences; 1:2000, $1 \mathrm{~h}$ at RT). In all cases, immunoreactivity was evaluated by enhanced chemiluminescence (ECL, SuperSignal West Dura Extended Duration Substrate; Thermo Fisher Scientific/ Pierce, Waltham, MA) and densitometric quantification of signal intensities assessed with ImageJ software (https:// imagej.nih.gov).

\section{Electron microscopy}

The presence of oligomeric forms of A $\beta 42$ in the culture supernatants was additionally assessed by electron microscopy using our previously described protocols [8, 
14]. Briefly, $3 \mu$ laliquots were placed onto carbon-coated 400-mesh $\mathrm{Cu} / \mathrm{Rh}$ grids (Ted Pella, Inc., Redding, CA, USA) and stained with $1 \%$ uranyl acetate in distilled water (Polysciences, Inc., Warrington, PA, USA). Stained grids were examined in a Philips CM-12 transmission electron microscope and photographed with a Gatan (4 $\mathrm{k} \times 4 \mathrm{k}$ ) digital camera at the NYU School of Medicine Microscopy Laboratory Core Facility.

\section{Detection of reactive oxygen species}

Generation of ROS was evaluated by IF using CellROX deep red (Thermo Fisher Scientific/Invitrogen) - a probe recognizing different ROS species including peroxyl/hydroxyl radicals and peroxynitrite-using previously reported lab methodologies [35, 36]. Primary cortical neurons and SH-SY5Y cells were seeded on poly-D-lysine-coated glass coverslips at a density of 300,000 cells/ coverslip, and challenged $24 \mathrm{~h}$ with increasing concentrations of $\mathrm{A} \beta 1-42(0-1 \mu \mathrm{M}$ for primary neurons, 0 $25 \mu \mathrm{M}$ in the case of SH-SY5Y), in the presence or absence of MTZ $(300 \mu \mathrm{M})$, MEL $(100 \mu \mathrm{M})$, or Trolox $(300 \mu \mathrm{M})$. After peptide treatment, cells were incubated with CellROX $\left(5 \mu \mathrm{M}, 30 \mathrm{~min}\right.$ at $\left.37^{\circ} \mathrm{C}\right)$ and Hoechst stain $(1 \mu \mathrm{g} / \mathrm{ml}$; Immunochemistry Technologies, Bloomington, $\mathrm{MN})$ followed by fixation in $4 \%$ paraformaldehyde (PFA). Images were acquired in a Nikon Eclipse $\mathrm{Ti}$ microscope and analyzed using ImageJ.

\section{Neuronal bioenergetic function and rate of oxidative metabolism of glucose}

Global neuronal cell metabolic/bioenergetic profiles were evaluated with XF Cell Mito Stress Assay in a Seahorse XFe24 analyzer (Seahorse Bioscience/Agilent Technologies, North Billerica, MA) - available through the NYU School of Medicine Translational Research Core-which allows real-time metabolic analysis in live cells. Primary neurons and SH-SY5Y cells were plated on PDL-coated Seahorse Xe24 plates (30,000 and 80,000 cells/per well, respectively) and challenged $24 \mathrm{~h}$ with various concentrations of $\mathrm{A} \beta 1-42(0-1 \mu \mathrm{M}$ for primary neurons and $0-20 \mu \mathrm{M}$ for neuroblastoma SH-SY5Y) in the presence or absence of $300 \mu \mathrm{M} \mathrm{MTZ,} 100 \mu \mathrm{M}$ MEL, or $300 \mu \mathrm{M}$ Trolox. Cells were subsequently washed with $\mathrm{XF}$ assay media or artificial CSF $[120 \mathrm{mM} \mathrm{NaCl}, 3.5 \mathrm{mM}$ $\mathrm{KCl}, 1.3 \mathrm{mM} \mathrm{CaCl}, 0.4 \mathrm{mM} \mathrm{KH_{2 }} \mathrm{PO}_{4}, 1 \mathrm{mM} \mathrm{MgCl} 2,5$ $\mathrm{mM}$ HEPES, $5.0 \mathrm{mM}$ glucose, $0.4 \%$ bovine serum albumin (BSA), pH 7.4] in the case of SHSY5Y cells or primary neurons, respectively. After washing, cells were further incubated in the respective media $\left(37^{\circ} \mathrm{C}, 1 \mathrm{~h}\right)$ in a $\mathrm{CO}_{2}$-free incubator to further purge $\mathrm{CO}_{2}$ and allow temperature/ $\mathrm{pH}$ equilibration before each set of measurements in the metabolic analyzer. Each plate contained four wells not seeded with neurons to serve as blank controls for temperature-sensitive fluctuations in
$\mathrm{O}_{2}$ fluorophore emission [37]. Following measurements of resting respiration, cells were sequentially treated with oligomycin $(1 \mu \mathrm{M})$ for the assessment of nonphosphorylating oxygen consumption rate (OCR), with the mitochondrial uncoupler FCCP $(2 \mu \mathrm{M})$ for the evaluation of maximal OCR, and with a combination of antimycin A and rotenone (both at $0.5 \mu \mathrm{M}$ ) for estimation of extra-mitochondrial OCR. In all cases, three measurements were recorded, each one over a 2-min interval followed by 2-min mixing and 2-min incubation.

At the end of the Seahorse runs, to allow a comparison among different experiments, data were normalized to the total cell amount per well as estimated by Janus Green Whole-Cell Stain (Sigma), an assay developed for anchorage-dependent cell cultures [38]. Briefly, cells were immediately fixed in 4\% PFA and incubated with Janus Green ( $0.2 \%$ ethanol solution, $5 \mathrm{~min})$. After removal of excess dye by ultrapure water washes, bound dye was eluted by $10 \mathrm{~min}$ incubation with $0.5 \mathrm{M} \mathrm{HCl}$ $(0.1 \mathrm{ml} /$ well $)$ and evaluated at $595 \mathrm{~nm}$ in a microplate reader (Packard SpectraCount, Cole-Parmer, Vernon Hills, IL). In all cases, the metabolic parameters of the assay-basal and maximal respiration, proton leak, and ATP production through oxidative phosphorylationwere calculated with Agilent/Seahorse XF Report Generator software and expressed as OCR in $\mathrm{pmol} / \mathrm{min}$. The results are illustrated as means \pm standard error from at least three to six independent experiments performed in triplicate.

\section{Assessment of Nrf2 pathway activation}

Evaluation of Nrf2 activation by MTZ, MEL, and Trolox in the presence or absence of $A \beta$ was performed through assessment of the translocation of the transcription factor to the nuclei by immunocytochemistry and dot and Western blot analysis of nuclear fractions, as well by ELISA evaluation of Nrf2 activity in these nuclear extracts.

\section{Immunocytochemistry}

SH-SY5Y cells and rat primary neurons were plated on PDL-coated coverslips and challenged with MTZ, MEL, or Trolox in the presence of varying $A \beta 42$ concentrations, as described above. After treatment, cells were fixed with $4 \%$ PFA, blocked with PBS containing $20 \mathrm{mg} /$ $\mathrm{ml}$ BSA $/ 0.3 \%$ Triton X-100, and incubated with rabbit polyclonal anti-Nrf2 antibody (Thermo Fisher/Invitrogen; $1: 500$ in PBS containing $5 \mathrm{mg} / \mathrm{ml} \mathrm{BSA}, 2 \mathrm{~h}$ at RT). After the primary antibody incubation, cells were subsequently reacted with Alexa Fluor 488-conjugated antirabbit IgG (Thermo Fisher/Invitrogen; 1:200 in PBS with $5 \mathrm{mg} / \mathrm{ml} \mathrm{BSA}, 1 \mathrm{~h}$ at RT) and Alexa Fluor 588-phalloidin (Thermo Fisher/Invitrogen; 1:200 in PBS with $5 \mathrm{mg} / \mathrm{ml}$ $\mathrm{BSA}, 1 \mathrm{~h}$ at RT), as previously described $[31,36]$. In the 
case of primary neurons, the Nrf2 antibody was coincubated with mouse monoclonal anti-neurofilament $70 \mathrm{kDa}$ antibody (clone DP5 2.7.3, Millipore-Sigma; 1: 200) followed by immunoreaction with a combination of Alexa 488-labeled anti-rabbit and Alexa 588-conjugated anti-mouse antibodies (1:200, each; $1 \mathrm{~h}, \mathrm{RT})$. All images were acquired using a Zeiss AxioImager microscope and analyzed using ImageJ software.

\section{Nuclear extract dot and Western blot analysis}

The activation of Nrf2 following SH-SY5Y and primary neurons A 342 challenge-with or without MTZ or MEL co-treatment-was analyzed in nuclear cellular fractions by dot and Western blot assessing the nuclear translocation of the transcription factor. Preparation of subcellular nuclear fractions was performed as previously reported by our laboratory [31, 36], a methodology resulting in high-purity nuclear extracts as evidenced by the almost complete absence of Western blot signal for the cytoplasmic markers $\alpha$-tubulin and GAPDH and the high positivity for nuclear histone 1 . Briefly, after the different treatments, cells were collected in homogenization buffer [ $75 \mathrm{mM}$ sucrose, $225 \mathrm{mM}$ mannitol, $5 \mathrm{mM}$ Tris$\mathrm{HCl} \mathrm{pH} \mathrm{7.4,} \mathrm{containing} \mathrm{protease} \mathrm{inhibitor} \mathrm{cocktail}$ (Roche Biochemical Reagents, Sigma)] and disrupted with the aid of a Dounce glass homogenizer. Cell homogenates were centrifuged (Eppendorf 5417R; 600×g, 5 $\min , 4^{\circ} \mathrm{C}$ ), nuclei recovered in the pellets, and lysed with RIPA buffer (Boston BioProducts, Ashland, MA); total protein content in the nuclear fractions was evaluated by BCA protein assay (Thermo Fisher Scientific/Pierce). For the dot blot assay, $20 \mu \mathrm{g}$ of the respective nuclear extracts was loaded in the wells and blocked membranes probed with the rabbit polyclonal anti-Nrf2 antibody (1: 500 , overnight at $4{ }^{\circ} \mathrm{C}$ ) followed by HRP-conjugated anti-rabbit IgG (GE Health Care Life Sciences; 1:5000, 1 $h$, RT) and ECL detection as above for A $\beta$ oligomerization dot blot. For the Western blot evaluation of Nrf2 nuclear translocation, $20 \mu \mathrm{g}$ each of the pertinent nuclear extracts was separated by $12 \%$ SDSPAGE under reducing conditions and electrotransferred to $0.45 \mu \mathrm{m}$ polyvinylidene difluoride membranes (PVDF, Thermo Fisher Scientific) for $1 \mathrm{~h} 45 \mathrm{~min}$ at $400 \mathrm{~mA}$ using $10 \mathrm{mM}$ 3-cyclohexylamino-1-propanesulfonic acid (CAPS, Sigma) buffer, pH 11.0, containing 10\% (v/v) methanol, as we previously described [31]. After blocking, the membranes were probed with anti-Nrf2 antibodies followed by HRP-conjugated anti-rabbit IgG, and finally developed by ECL, as for the dot blot. As loading controls for the dot and Western blot analyses, the membranes were stripped with Restore Plus Western blot stripping buffer (Thermo Fisher Scientific) and immunoreacted with rabbit polyclonal anti-GAPDH antibodies (Abcam, Cambridge, MA; 1:1000, overnight,
$4{ }^{\circ} \mathrm{C}$ ) followed by HRP-conjugated anti-rabbit IgG (GE Health Care Life Sciences; 1:5000, 1 h, RT).

\section{Nrf2 activity ELISA}

Active nuclear Nrf2 was evaluated using Nrf2 activity ELISA (Abcam) which quantitates Nrf2 able to bind to immobilized oligonucleotides containing the ARE consensus motif. Twenty micrograms of each of the nuclear protein extracts was loaded onto microtiter wells pre-coated with the specific double-stranded DNA sequence containing the Nrf2 consensus binding site (5'-GTCACAGTGA CTCAGCAGAATCTG-3'). Active Nrf2 specifically captured by the oligonucleotide motif was detected by incubation with a primary antibody recognizing an $\mathrm{Nrf} 2$ epitope accessible only after protein activation and subsequent binding to its target DNA. This was followed by detection with HRP-conjugated secondary antibody and colorimetric readout at $450 \mathrm{~nm}$ in accordance with the manufacturer's protocol.

\section{Evaluation of Nrf2-mediated antioxidant response}

Changes in the activation of Nrf2 downstream antioxidant response were assessed through the immunocytochemical analysis of SOD1 and HO-1 in SH-SY5Y cells as well as in primary neurons grown on glass coverslips. After treatment with MTZ, MEL, and Trolox in the presence/absence of $\mathrm{A} \beta 42$, cells were fixed, and non-specific binding blocked as described above. This was followed by incubation with anti-SOD1 and anti-HO1 primary antibodies (Thermo Fischer/Invitrogen, $1: 500$ and 1:200, respectively, in PBS containing $5 \mathrm{mg} / \mathrm{ml} \mathrm{BSA}, 2 \mathrm{~h}$ at $\mathrm{RT}$ ) and subsequent reaction with the pertinent Alexa Fluor 488-conjugated antirabbit and anti-mouse IgG antibodies (Thermo Fisher/Invitrogen; 1:200 in PBS with $5 \mathrm{mg} / \mathrm{ml}$ BSA, 1 $h$ at $\mathrm{RT}$ ). The nuclei were counterstained with DAPI containing mounting medium (Verashield, Vector Laboratories, Burlingame, CA). Image acquisition and analysis were performed as above for the assessment of Nrf2.

\section{Assessment of methazolamide-, melatonin-, and Trolox- mediated Nrf2 activation pathway}

Evaluation of the Nrf2 activation path elicited by MTZ, MEL, and Trolox was performed through assessment of the transcription factor nuclear translocation in the presence of PI3K and GSK-3 inhibitors, using as control cells incubated with SFN $(5 \mu \mathrm{M})$, a compound capable of activating Nrf2 through disruption of its binding to Keap-1, a PI3K-independent pathway. SH-SY5Y cells plated on PDL-coated coverslips were challenged with the Nrf2 activators MTZ, MEL, Trolox, and SFN at the concentrations specified above in the presence of either the PI3K inhibitors LY294002 and Wortmannin (10 $\mu \mathrm{M}$ each) or 
the GSK-3 inhibitor SB216763 $(10 \mu \mathrm{M})$ followed by evaluation of Nrf2 nuclear localization by immunocytochemistry as well as dot and Western blot analysis of nuclear extracts using the same procedures described above. Changes in the activation of Nrf2 downstream antioxidant response in the presence of PI3K and GSK-3 inhibitors was assessed through the immunocytochemical analysis of SOD1 and HO1, under identical conditions as above.

\section{Statistical analysis}

Multiple comparison analyses were performed by ANOVA with Dunnett post hoc test using GraphPad (GraphPad, La Jolla, CA). Values of $p \leq 0.05$ were considered significant.

\section{Results \\ A 342 forms oligomeric assemblies in cell conditioned media}

The formation of oligomeric assemblies during our experimental window was monitored by dot blot analysis probed with A11 anti-oligomer antibody whereas the final assessment of the conformational structures was evaluated by transmission electron microscopy. Figure 1 illustrates the characteristics of $\mathrm{A} \beta 42$ species in conditioned media of cells challenged with the peptide for $24 \mathrm{~h}$, showing the presence of oligomeric structures of $<100 \mathrm{~nm}$ in length that were immunoreactive with the A11 antibody (right panel). As a control, freshly solubilized HFIP-treated A 342 lacked A11 immunoreactivity and failed to show similar structures under EM (left panel).

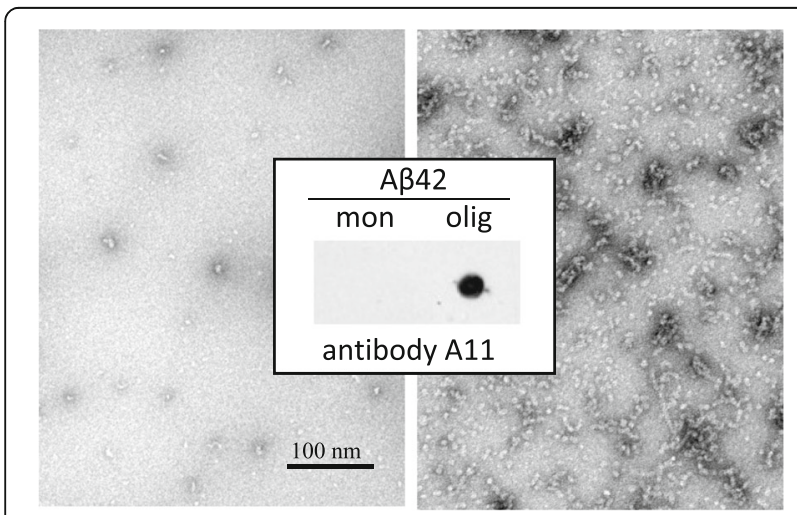

Fig. 1 A 442 oligomeric structures visualized by dot blot and electron microscopy. The presence of oligomeric forms of $A \beta 42$ in the culture supernatants was assessed by dot blot analysis probed with anti-oligomer antibody A11 as well as by electron microscopy after negative staining. Left panel: freshly solubilized HFIP-treated A 42 ; right panel: conditioned media of cells challenged with $A \beta 42$ for $24 \mathrm{~h}$. Bar, $100 \mathrm{~nm}$
$A \beta 42$ induces mitochondria-mediated changes in neuronal metabolic profiles

Oxygen consumption by SH-SY5Y cells and fully differentiated DIV7 primary rat cortical neurons [39] was measured in the Seahorse XFe24 Extracellular Flux Analyzer which has become a reference method for analyzing mitochondrial function in intact cells. Basal respiration necessary to meet cellular energy demand is typically limited by the rate at which ATP is hydrolyzed, which in turn determines the rate of transmitochondrial membrane proton cycling into the matrix through ATP synthetase and out of the matrix through components of the electron transport chain. As shown in Fig. 2, baseline OCR values were stable in both cell types during the first $20 \mathrm{~min}$. The addition of oligomycin decreased OCR in both cases to approximately the same extent $-25 \%$ and $20 \%$ of basal respiration levels for SHSY5Y and primary neurons, respectively-indicating low levels of oligomycin-resistant OCR attributable to proton leakage. Subsequent addition of the proton ionophore FCCP elicits the maximal rate at which $\mathrm{O}_{2}$ is consumed. The compound collapses proton electrochemical gradients permitting the maximal functioning of the respiratory chain without limitation by a positive outside membrane potential. As a result, FCCP uncouples respiration from ATP synthesis allowing determination of the maximal respiratory capacity of the electron transport chain only limited by substrate supply. In our system, FCCP completely restored basal respiration levels in SH-SY5Y cells and increased OCR values in $~ 60 \%$ in DIV7 neurons, consistent with previous findings [39, 40]. The difference in the FCCP response between $\mathrm{SH}$ SY5Y and primary neurons likely reflects neuronal differentiation, as it has been reported that while maximal respiration did not increase above basal levels in nondifferentiated cells, FCCP-induced OCR values were significantly higher in differentiated neurons [39]. At the final steps of the Seahorse run, the addition of the respiratory complex I inhibitor rotenone in combination with the complex III inhibitor antimycin allowed evaluation of non-mitochondrial OCR, an index of oxygen-consuming processes unrelated to the mitochondrial activity. In our system, the addition of these inhibitors resulted in $>90 \%$ inhibition of OCR, confirming that for both SH-SY5Y and primary neurons, the levels of $\mathrm{O}_{2}$ consumption are almost exclusively related to mitochondrial respiration, following the trend observed in most cell types [41].

Incubation with $A \beta 42$ at concentrations and in a time frame in which the peptide does not induce cell toxicity $[7,35,42]$ changed the bioenergetic profiles of both $\mathrm{SH}$ SY5Y and primary neuron cells in a dose-dependent manner, albeit it should be noted that primary neurons were more susceptible to the effect of the peptide with 


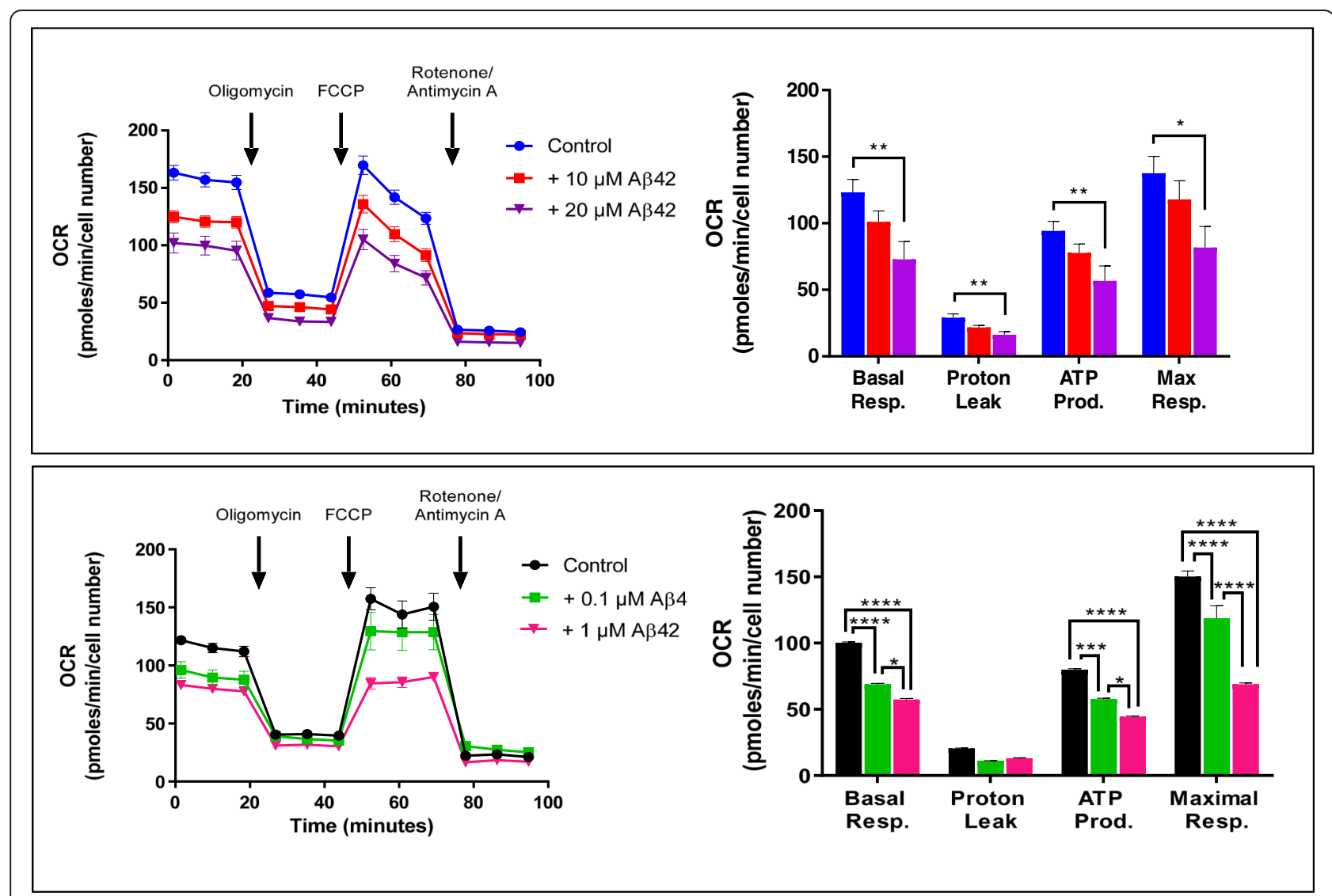

Fig. 2 Aß42-mediated metabolic/bioenergetic changes in SH-SY5Y cells and rat primary cortical neurons. Both cell types were incubated $24 \mathrm{~h}$ in the presence of increasing concentrations of $\mathrm{A} \beta 42$ and analyzed through the use of Cell Mito Stress Assay in a Seahorse platform as described in the "Material and methods" section. Panels on the left illustrate the real-time kinetic rate of oxygen consumption (OCR) versus time and indicate the injection time of the different modulators of the respiratory chain. Right panels depict the test parameters calculated with Seahorse XF Report Generator software. In all cases shown, OCR levels were normalized to DNA content assessed by Janus Green staining; bar graphs illustrate means \pm SEM from at least three to six independent experiments performed in triplicate. ${ }^{*} p<$ $0.05,{ }^{* *} p<0.01,{ }^{* *} p<0.001$, and ${ }^{* * *} p<0.0001$

comparable responses elicited at much lower doses. Figure 2 illustrates the $A \beta$-induced changes in the real-time metabolic parameters. A $\beta 42$ caused a significant reduction in basal respiration calculated by subtracting nonmitochondrial respiration-OCR values after antimycin A/rotenone injection-from baseline respiration levels (Additional file 1: Figure S1). In SH-SY5Y cells (Fig. 2, panel A) basal OCR levels reached $\sim 54 \%$ of OCR control values after incubation with $20 \mu \mathrm{M} A \beta 42$, the highest concentration tested in our system since higher $A \beta$ doses caused significant cell death [31, 35]. Notably, a comparable 55\% OCR reduction was elicited in primary neurons (panel B) by $1 \mu \mathrm{M} \mathrm{A} \beta 42$, a 20 -fold lower concentration. In addition, $A \beta 42$ significantly decreased maximal respiration calculated by subtraction of nonmitochondrial respiration values from the maximum respiration levels induced by injection of FCCP (Additional file 1: Figure S1). As illustrated in Fig. 2, SH-SY5Y maximal respiration was reduced by incubation with $20 \mu \mathrm{M} \mathrm{A} \beta 42$ to levels $~ 55 \%$ of those in untreated control cells. In the case of primary neurons, a much lower $1 \mu \mathrm{M} A \beta 42$ concentration decreased OCR to $\sim 39 \%$ of untreated control levels. Another metabolic parameter affected by $A \beta$ is the proton leak, calculated by subtracting non-mitochondrial OCR values from respiration levels in the presence of the ATP synthase inhibitor oligomycin (Additional file 1: Figure S1). In both neuronal cells, the low proton leak levels observed $(\sim 10 \%$ of basal respiration) indicate that $\mathrm{O}_{2}$ consumption is primarily coupled to ATP production. The addition of $\mathrm{A} \beta 42$ appears to reduce these values even more likely indicating that the damage to oxidative phosphorylation induced by the peptide impedes the flow of electrons thereby resulting in even lower OCR values. $A \beta 42$ also caused a significant decrease in $\mathrm{O}_{2}$ consumption linked to ATP production which is evaluated in the metabolic analyzer as the difference between basal and oligomycin-insensitive OCR measurements 
(Additional file 1: Figure S1). As with the other metabolic parameters, incubation with $\mathrm{A} \beta 42$ induced a similar reduction in ATP production in primary neurons albeit at 20-fold lower doses than in SH-SY5Y $(\sim 60 \%$ reduced values in $1 \mu \mathrm{M}$-treated primary neurons versus $\sim 56 \%$ of control values in SH-SY5Y challenged with $20 \mu \mathrm{M} \mathrm{A} \beta 42$ ).

Overall, A $\beta 42$ caused a significant decrease in all Seahorse-assessed metabolic parameters in SH-SY5Y and primary neurons although the latter were more susceptible to the effect of the peptide and comparable changes were notable at much lower doses. Whether these differences relate to the differentiation state of the cells remains to be elucidated, albeit it has been previously demonstrated during ex vivo differentiation of primary cortical neurons that neuronal development significantly modifies mitochondrial activity and global metabolic parameters [39].
Methazolamide, melatonin, and Trolox rescue $A \beta 42-$ induced changes in neuronal metabolic/bioenergetic profiles

Previous work from our laboratory as well as from other groups has demonstrated a protective effect of a number of compounds on $A \beta$-induced cellular toxicity and mitochondrial activity, among them MTZ, MEL, and Trolox $[8,24,26,35,43]$. These three compounds were tested for their ability to circumvent the effect of $A \beta 42$ in the metabolic parameters evaluated in the Seahorse platform at a concentration previously shown as protective from $\mathrm{A} \beta$-mediated mitochondrial cytochrome $\mathrm{c}$ release and induction of apoptosis, a dosage at which the compounds did not exhibit toxicity [8, 23, 24, 26, 35, 43]. Figure 3 illustrates the metabolic profile of $A \beta 42-$ challenged SH-SY5Y and primary cortical neurons (panels a and b, respectively) in the presence of a 300$\mu \mathrm{M}$ dose of MTZ, a concentration that in our previous

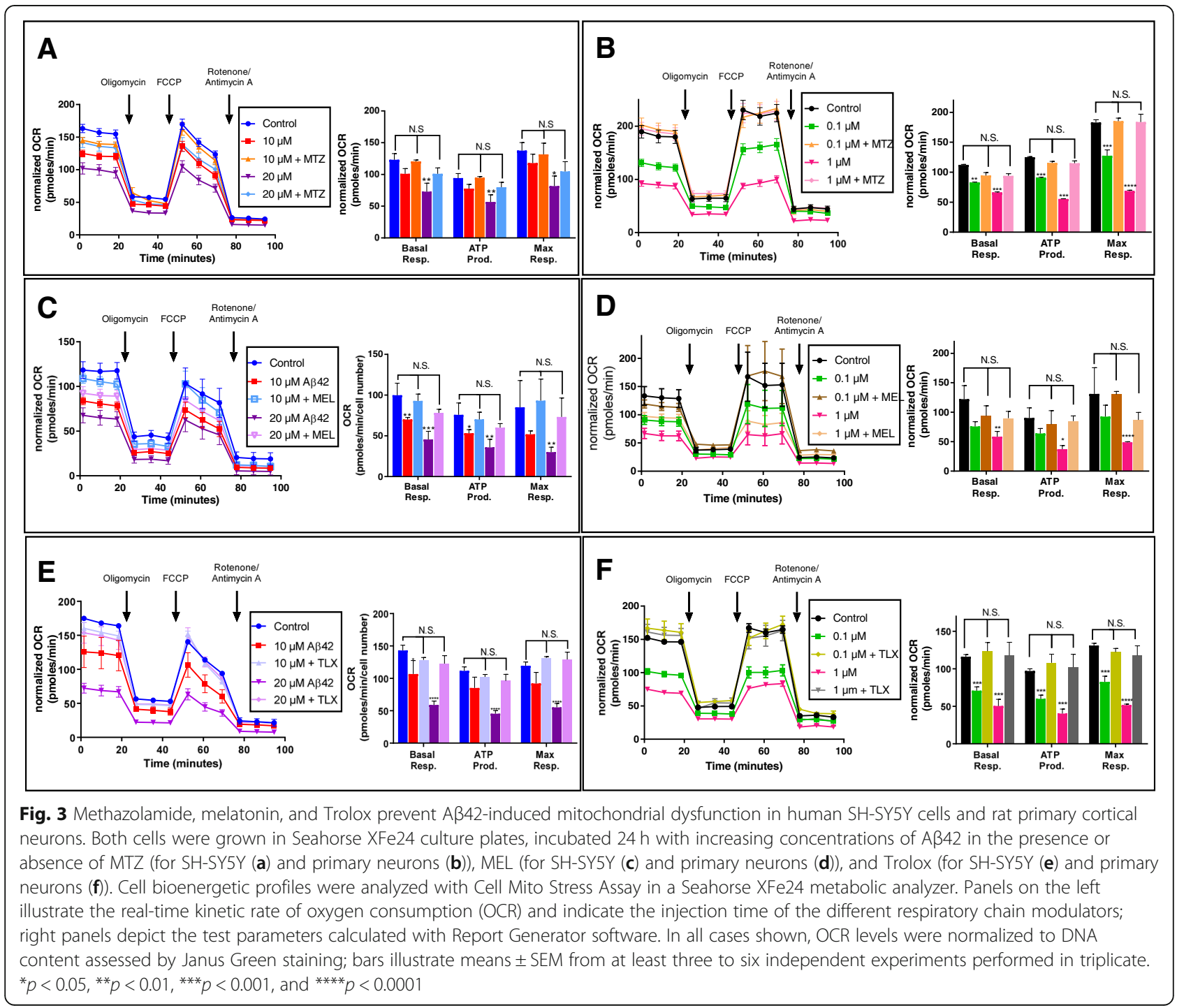


work protected $\mathrm{SH}$-SY5Y cells from $\mathrm{A} \beta$-mediated mitochondrial cytochrome $\mathrm{c}$ release and prevented downstream activation of caspase- 3 and subsequent apoptosis $[24,31]$. As depicted in the figure, MTZ rescues the metabolic/bioenergetic deficits induced by the peptide, restoring basal and maximal respiration as well as ATP production to the levels of untreated SH-SY5Y and cortical neurons controls.

Figure 3 also illustrates the protective effect of MEL in circumventing the detrimental effect of $A \beta 42$ in neuronal cells. The decrease in all mitochondriamediated metabolic parameters observed in $A \beta$ challenged SH-SY5Y and cortical neurons (panels $\mathrm{c}$ and $\mathrm{d}$, respectively) was restored to control levels by treatment with $100 \mu \mathrm{M}$ MEL, a non-toxic concentration in the range of previously reported antioxidant activity of the compound [22, 23, 26, 44]. Basal and maximal respiration, as well as $\mathrm{O}_{2}$ consumption linked to ATP production, were all restored to levels non-statistically different from those of non-A $\beta$ treated neurons. The protective effect of MTZ and MEL in neuronal metabolic profiles was also recapitulated by treatment with Trolox, a vitamin E analog with high ROS-scavenging capacity that is used as a standard for the evaluation of the antioxidant capability of other compounds $[45,46]$. As illustrated in Fig. 3e, f, co-incubation of A 342 -challenged SH-SY5Y cells and cortical neurons with $300 \mu \mathrm{M}$ Trolox, a dose capable of protecting cells from amyloid-mediated ROS generation $[35,36]$, rescued the decrease induced by the $\mathrm{A} \beta$ peptide in basal and maximal respiration, as well as ATP production levels. The protective effect of MTZ, MEL, and Trolox likely results from the capability of the compounds to increase mitochondrial function in the Seahorse platform as indicated by their ability to increase basal and maximal respiration when incubated $24 \mathrm{~h}$ with SH-SY5Y cells in the absence of $A \beta$ (not shown).

\section{Methazolamide, melatonin, and Trolox protect neuronal cells from the $A \beta$-mediated generation of reactive oxygen} species

Oxidative stress, often linked to mitochondrial dysfunction, is integral to many cell death programs and has been associated with the progression of a number of neurodegenerative disorders $[47,48]$. SH-SY5Y cells and primary cortical neurons challenged $24 \mathrm{~h}$ with increasing concentrations of $\mathrm{A} \beta 42(0-25 \mu \mathrm{M}$ and $0-1 \mu \mathrm{M}$, respectively) displayed a progressive generation of reactive oxygen species (ROS), as highlighted by the free radical sensing fluorogenic probe CellROX (Figs. 4 and 5, respectively). This ROS generation was completely blocked by treatment with the protective agents MTZ, MEL, and Trolox at a concentration at which the compounds do not exhibit cell toxicity. The bar graphs in each figure illustrating the quantitation of the red fluorescent signal, normalized to DAPI staining intensity, clearly indicate the dose response of ROS buildup with increasing concentrations of the peptide, as well as the complete inhibition of ROS generation in the presence of MTZ, MEL, and Trolox all of which bring back levels to values that do not statistically differ from those of non-A $\beta$-treated

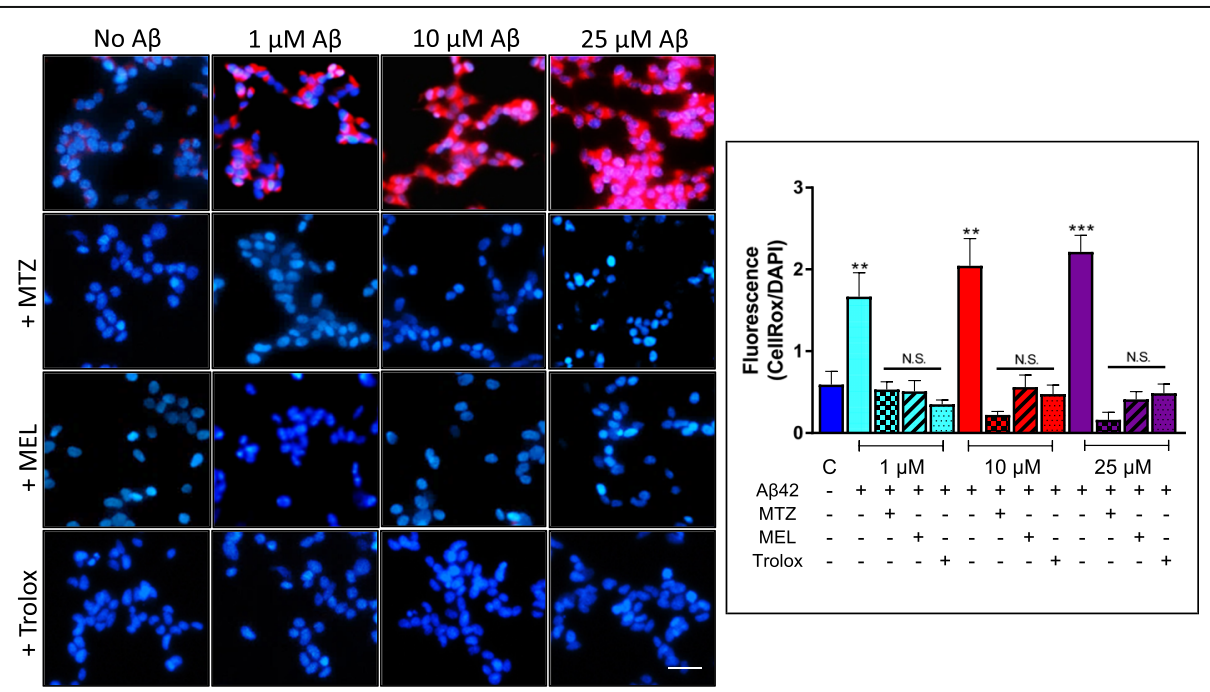

Fig. 4 Methazolamide, melatonin, and Trolox protect from Aß-mediated ROS generation in SH-SY5Y. Following $24 \mathrm{~h}$ incubation with Aß42 (0$25 \mu \mathrm{M})$ in the presence or absence of MTZ $(300 \mu \mathrm{M})$, MEL $(100 \mu \mathrm{M})$, and Trolox $(300 \mu \mathrm{M})$, ROS-generated species were detected with CellROX $(5 \mu \mathrm{M})$, and nuclei counterstained with Hoechst $(1 \mu \mathrm{g} / \mathrm{ml})$. Images depict CellRox fluorescence (red signal) and DAPI DNA counterstaining; bar, $25 \mu \mathrm{m}$. The graph on the right illustrates the quantitation of CellROX fluorescence values normalized to DAPI signal using ImageJ analysis software; data is represented as mean \pm SEM. ${ }^{* *} p<0.01$ and ${ }^{* * *} p<0.001$ 

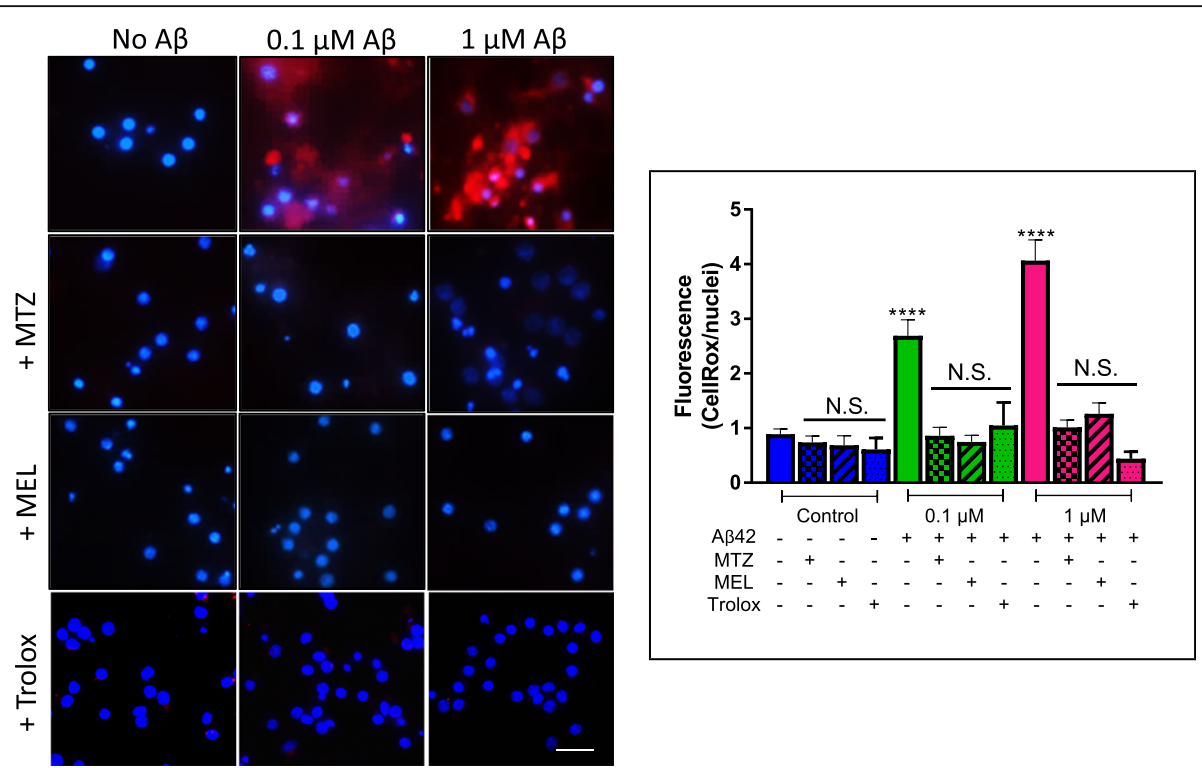

Fig. 5 Methazolamide, melatonin, and Trolox prevent Aß-mediated ROS generation in primary cortical neurons. Primary neurons were treated with various concentrations of A $342(0-1 \mu \mathrm{M})$ in the presence or absence of MTZ $(300 \mu \mathrm{M})$, MEL $(100 \mu \mathrm{M})$, and Trolox $(300 \mu \mathrm{M})$, subsequently stained with CellROX, and nuclei counterstained with Hoechst, as in Fig. 4. Immunofluorescence images illustrate ROS formation highlighted by the free radical sensing probe CellROX (red signal) and nuclei staining with DAPI (blue fluorescence); bar, $25 \mu \mathrm{m}$. The graph depicts the quantitation of CellROX fluorescence normalized to DAPI signal with ImageJ software; data is represented as mean \pm SEM. ${ }^{* * *} p<0.0001$

control cells. Whether the compounds are capable of reversing $\mathrm{A} \beta$-induced changes, once the detrimental effect of the peptide has occurred, remains to be elucidated.

\section{Effect of methazolamide, melatonin, and Trolox on $A \beta$ oligomerization}

Our previous reports as well as work from other laboratories have demonstrated the key role exerted by $A \beta$ oligomerization in the induction of mitochondriamediated cell death pathways [7, 8, 24, 31, 35]. To assess whether the protective effect of MTZ, MEL, and Trolox on the $A \beta$-mediated metabolic, bioenergetic, and oxidative changes illustrated above resulted from changes in $\mathrm{A} \beta$ oligomerization induced by the compounds, we performed dot blot analysis using the anti- $\mathrm{A} \beta$ oligomer $\mathrm{A} 11$ antibody. In the assay, the conditioned media of triplicate experiments in which SH-SY5Y cells challenged 24 $h$ with $A \beta 42$ in the presence and absence of MTZ, MEL, and Trolox were probed with the anti-oligomer antibody. As illustrated in Fig. 6, no changes in the oligomer signal intensity were observed upon treatment with the protective compounds under the current experimental
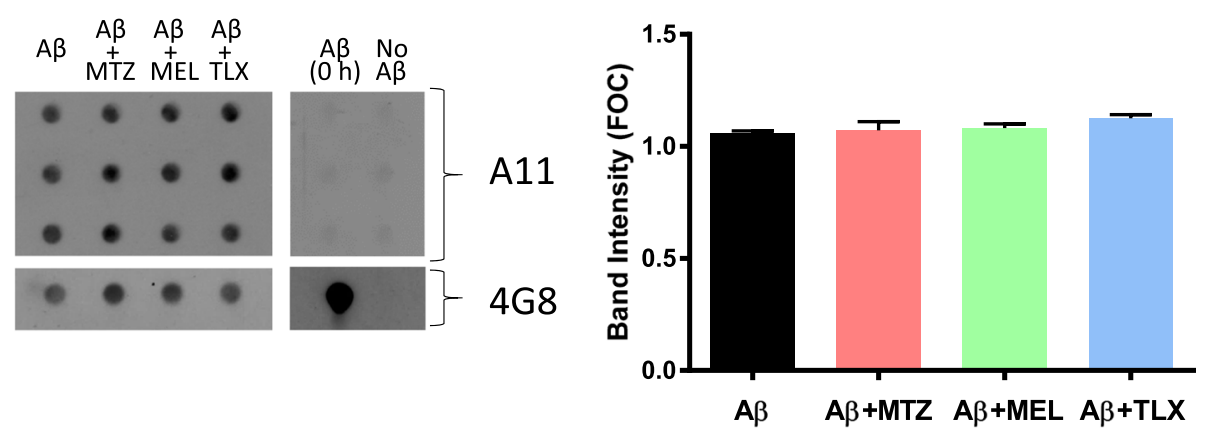

Fig. 6 Lack of effect of methazolamide, melatonin, and Trolox on A oligomerization. Oligomer A $\mathrm{B}$ immunoreactivity in cell culture supernatants from SH-SY5Y cells treated $24 \mathrm{~h}$ with Aß42 $(10 \mu \mathrm{M})$ in the presence/absence of MTZ $(300 \mu \mathrm{M})$, MEL $(100 \mu \mathrm{M})$, or Trolox $(300 \mu \mathrm{M})$ was assessed by dot blot analysis. The respective supernatants of triplicate experiments were loaded onto the nitrocellulose membrane and probed with A11 antioligomer antibody, as described in the "Material and methods" section. Reactivity with 4G8 anti-A 3 antibody was used as a loading control. Right panel depicts the immunoreactivity of membranes loaded with freshly prepared synthetic A $442(800 \mathrm{ng})$ as a negative control for oligomer formation. Histograms on the right panel illustrate the densitometric quantification of the dot blot A11 signal intensities normalized to the respective $4 \mathrm{G} 8$ controls; data are represented as mean \pm SEM 
conditions. As a control, and consistent with previous reports [8], the figure highlights the lack of A11 reactivity of freshly solubilized HFIP-treated $A \beta 42$ while reactivity with monoclonal $4 \mathrm{G} 8$ anti-A $\beta$ antibody was used as a loading control.

\section{Methazolamide, melatonin, and Trolox activate Nrf2 transcription factor and the downstream antioxidant response}

Based on the lack of effect of MTZ, MEL, and Trolox on $A \beta$ oligomerization, we looked into whether the protective effects of the compounds resulted from activation of Nrf2, a central regulator of the antioxidant response [49, 50]. As the first step, we evaluated the nuclear translocation of the transcription factor induced by the compounds in SH-SY5Y and primary neurons by immunocytochemistry. Figures 7 and 8 illustrate the increase in the nuclear Nrf2 green fluorescent signal induced by MTZ, MEL, and Trolox in both cell types in comparison with the low endogenous levels of expression present in untreated control cells. Notably, the addition of $A \beta$ to the cells did not result in Nrf2 activation at any of the $A \beta$ concentrations tested in spite of the ROS-inducing activity of the peptide illustrated in Figs. 4 and 5. The Nrf2 nuclear translocation observed following MTZ, MEL, and Trolox treatment of A $\beta$ challenged cells suggests that the protective action of the compounds from the detrimental effect of the peptide is likely driven by the induction of Nrf2-mediated antioxidant response defense mechanisms.
Confirmation of Nrf2 activation by MTZ, MEL, and Trolox was assessed by Nrf2 activity ELISA, a test with a lower detection limit of $0.6 \mu \mathrm{g}$ nuclear extract/well. After a separate treatment of $\mathrm{A} \beta$-challenged SH-SY5Y and primary neurons with the different compounds and preparation of nuclear extracts, the capability of the transcription factor in these fractions to bind the ARE motif was evaluated through Nrf2 ELISA activity assay following the protocols described in the "Material and methods" section. As illustrated in Fig. 7, right panel, nuclear active Nrf2 more than doubled with the addition of MTZ, MEL, and Trolox to control non-A $\beta$-treated SH-SY5Y cells. The enhanced nuclear expression of Nrf2 caused by the compounds was also observed in the presence of $A \beta 42$, likely accounting for their protective effect from A $\beta 42$ described above. MTZ, MEL, and Trolox exhibited a comparable effect in enhancing the levels of nuclear active Nrf2 in primary cortical neurons (Fig. 8, right panel). The activation of $\mathrm{Nrf2}$ elicited by the three compounds in both $A \beta$ - and non- $\mathrm{A} \beta$-challenged $\mathrm{SH}$ SY5Y cells and primary neurons translated, in all cases, in downstream increased expression of SOD-1 and HO1 , as illustrated by the immunocytochemical evaluation of both enzymes. Figure 9 illustrates the cytoplasmic increment of SOD-1 (Fig. 9a) and HO-1 expression (Fig. 9b) following 24 $\mathrm{h}$ incubation with MTZ, MEL, and Trolox in SH-SY5Y. All compounds produced statistically significant differences of about 2 -fold increase in the levels of cytoplasmic SOD-1 signal and $\sim 1.5$-fold increase in $\mathrm{HO}-1$ fluorescence intensity compared to
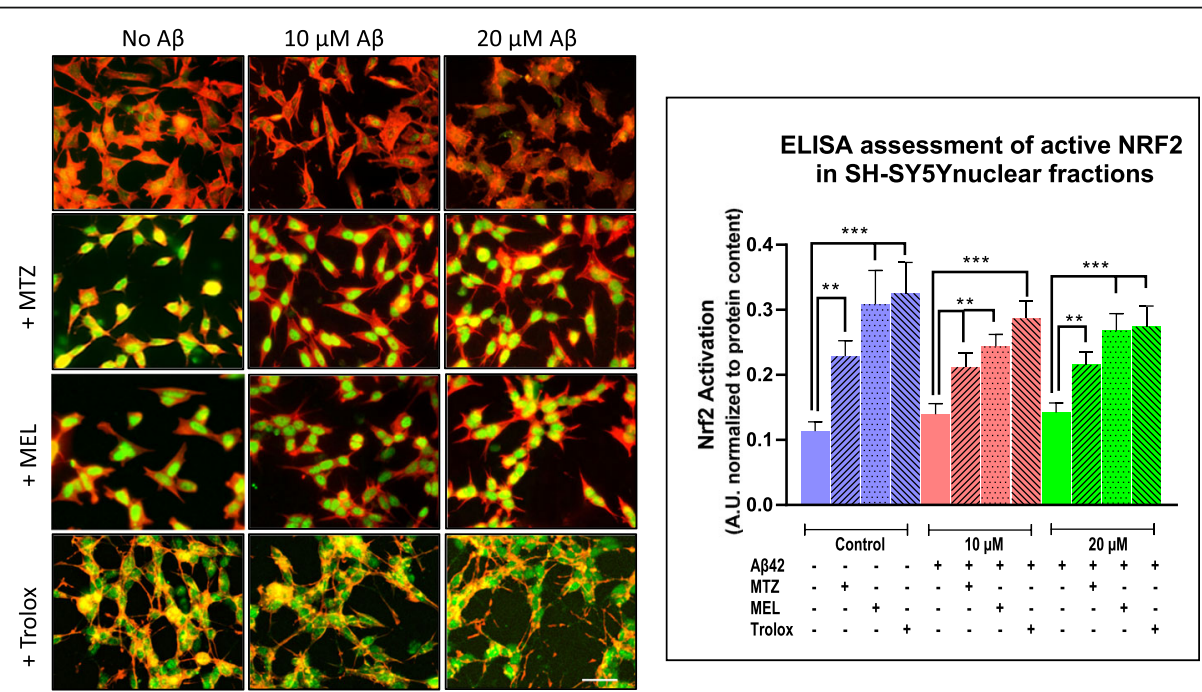

Fig. 7 Methazolamide, melatonin, and Trolox activate Nrf2 nuclear translocation in SH-SY5Y cells. SH-SY5Y cells were treated with various concentrations of A $42(0-20 \mu M)$ in the presence/absence of MTZ, MEL, or Trolox. Nrf2 nuclear translocation was assessed by incubation with rabbit polyclonal anti-Nrf2 antibody followed by Alexa-488 conjugated anti-rabbit lgG, as detailed in the "Materials and methods" section. Actin was highlighted by immunoreaction with Alexa-588 conjugated phalloidin. Immunofluorescence images depict Nrf2 nuclear signal (green fluorescence) and actin staining (red signal); bar, $25 \mu \mathrm{m}$. The graph illustrates the Nrf2 activity in nuclear extracts evaluated by ELISA through the quantitation of Nrf2 binding to immobilized oligonucleotides containing the ARE consensus motif. Bars represent mean \pm SEM of triplicate experiments. ${ }^{* *} p<0.01$ and ${ }^{* *} p<0.001$ 


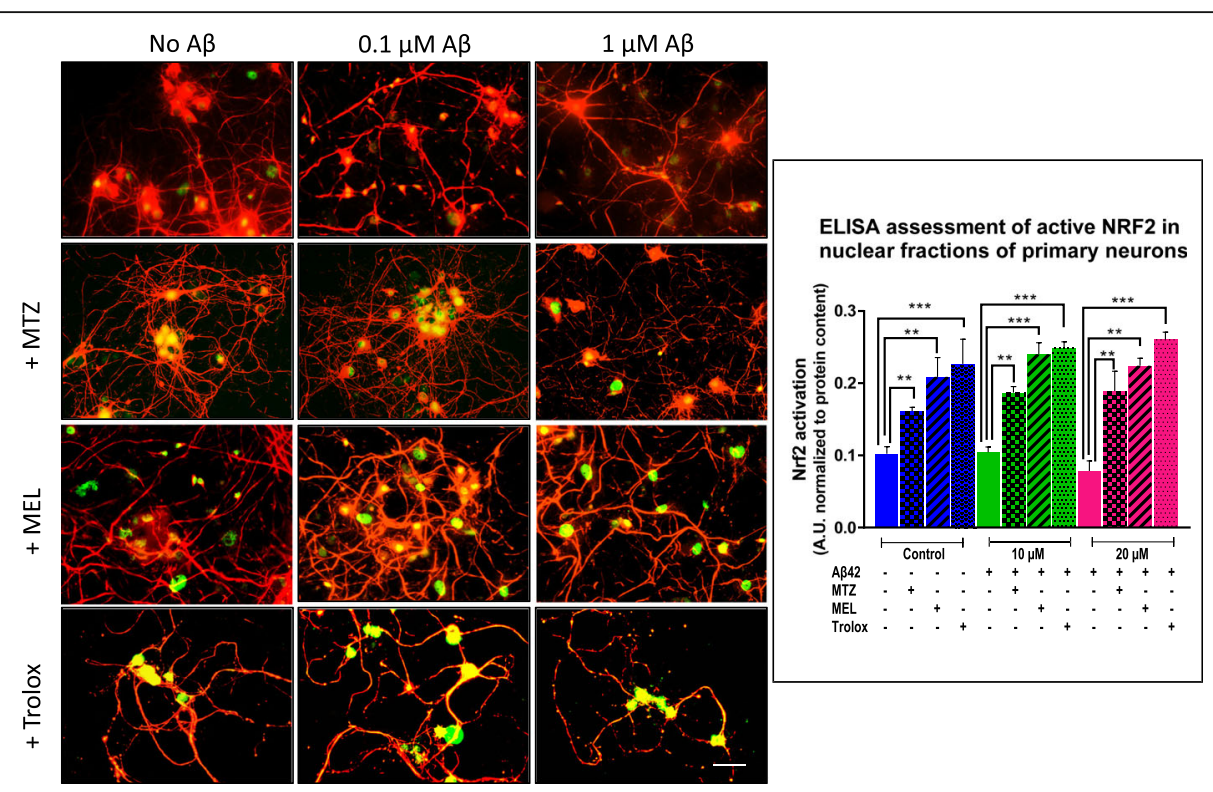

Fig. 8 Methazolamide, melatonin, and Trolox induce Nrf2 activation in primary neurons. Cortical neuron cultures were challenged with various concentrations of A $442(0-1 \mu \mathrm{M})$ in the presence or absence of either MTZ $(300 \mu \mathrm{M})$, MEL (100 $\mu \mathrm{M})$, or Trolox $(300 \mu \mathrm{M})$ and Nrf2 assessed by immunofluorescence microscopy as in Fig. 7. Immunofluorescence images depict Nrf2 nuclear translocation (green signal) and neurofilament protein staining (red fluorescence); bar, $25 \mu \mathrm{m}$ in all images. The graph illustrates the Nrf2 activity in nuclear extracts evaluated by ELISA. Bars represent mean \pm SEM of triplicate experiments. ${ }^{* *} p<0.01$ and ${ }^{* * *} p<0.001$

untreated control cells as evaluated using ImageJ software. Similarly, Fig. 10a, b depicts a comparable effect of MTZ, MEL, and Trolox in primary cortical neurons. All compounds produced a statistically significant difference of $\sim 2$ to 2.5 -fold increase in the levels of cytoplasmic SOD-1 and HO-1 green fluorescent signal compared to untreated control primary neurons.

\section{Methazolamide, melatonin, and Trolox activate Nrf2 and its downstream antioxidant response proteins through the PI3K/GSK-3 axis}

Figure 11 illustrates the two major pathways of Nrf2 degradation and activation, one mediated by its binding to Keap1 (Kelch-like ECH-associated protein 1) and the other regulated by glycogen synthase kinase 3 (GSK-3). Nrf2 activation was evaluated assessing its nuclear translocation and subsequent triggering of the antioxidant proteins SOD1 and HO-1 in SH-SY5Y cells and primary neurons incubated with MTZ, MEL, and Trolox in the presence/absence of PI3K and GSK-3 inhibitors. As illustrated in Fig. 12, MTZ and MEL challenge of SHSY5Y cells and primary neurons in the presence of the PI3K inhibitor LY294002, almost completely abolished the dot and WB Nrf2 signal in the respective nuclear fractions suggesting that the activation of Nrf2 by the two compounds takes place through the PI3K/Akt axis. Additional corroboration was obtained with the use of the GSK-3 inhibitor SB216763. Under normal conditions, GSK-3 targets Nrf2 for proteosomal degradation through its phosphorylation and subsequent binding to the $\beta \operatorname{TrCP}$ E3 ubiquitin ligase complex (Fig. 11). GSK-3 inhibition precluded Nrf2 degradation resulting in its enhanced expression and nuclear translocation evidenced by the dot and WB signal intensities (Fig. 12), further implicating the PI3k/Akt-GSK-3 axis in the activation pathway elicited by MTZ and MEL.

Validation of Nrf2 nuclear translocation and concomitant increase in the expression of the antioxidant proteins SOD1, and HO-1 was performed by immunocytochemistry in SH-SY5Y cells incubated with MTZ, MEL, and Trolox as well as with the electrophilic compound SFN, in the presence/absence of PI3K and GSK-3 inhibitors. As illustrated by the images in Fig. 13 and their quantitative assessment in Additional file 2: Figure S2, the addition of the PI3K inhibitors Wortmannin and LY294002 resulted in complete inhibition of Nrf2 activation as evidenced by the lack of nuclear fluorescence signal strongly suggesting that the activation of Nrf2 by MTZ, MEL, and Trolox takes place through the PI3K/ Akt-GSK-3 axis. Additional corroboration was obtained with the use of the GSK-3 inhibitor SB216763. GSK-3 inhibition precluded Nrf2 degradation through the $\beta$ TrCP path resulting in its enhanced nuclear expression, further implicating the PI3k/Akt-GSK-3 axis in the activation mechanism elicited by MTZ, MEL, and Trolox (Fig. 13). In contrast, cells challenged with SFN-an electrophilic compound known to activate Nrf2 through disruption of the binding to its transport protein Keap1, 

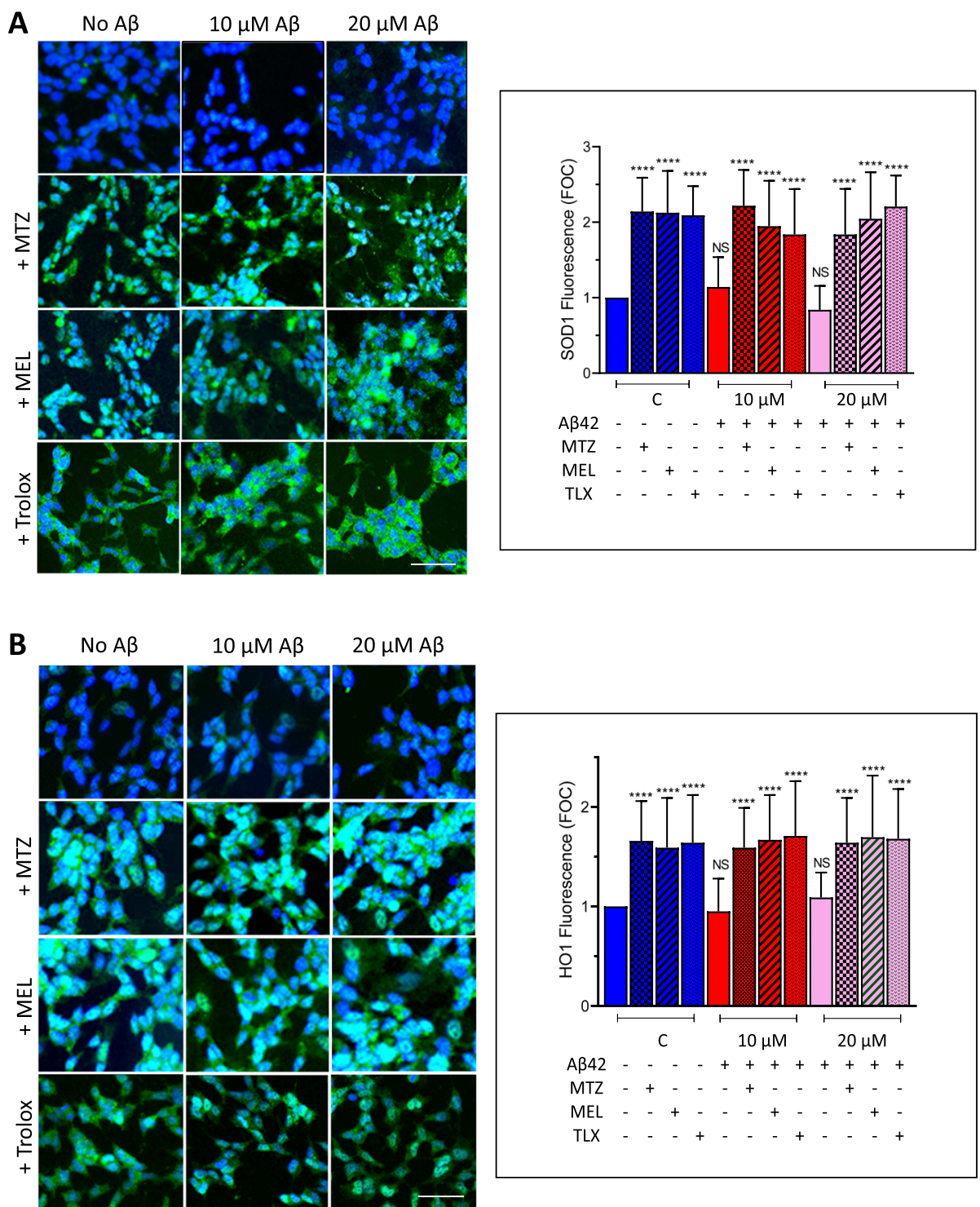

Fig. 9 Translational activation of the downstream Nrf2 targets SOD-1 and HO-1 by methazolamide, melatonin, and Trolox in SH-SY5Y cultures. Cells were treated with the Nrf2 activators MTZ, MEL, and Trolox in the presence/absence of A $42(0-20 \mu \mathrm{M})$ followed by immunodetection of SOD1 and HO-1 expression by incubation with the pertinent primary antibodies and subsequent immunoreaction with Alexa-488 conjugated secondary antibodies. Green fluorescence highlights SOD-1 (a) and HO-1 (b) immunoreactivity; blue fluorescence depicts DAPI nuclear DNA counterstaining. Bar, $25 \mu \mathrm{m}$ in all cases. The graphs in $\mathbf{a}$ and $\mathbf{b}$ depict respectively the quantitation of SOD-1 and HO-1 fluorescence signal in at least 400 cells utilizing ImageJ software and expressed in fold of control. Data is represented as mean $\pm \mathrm{SD} ;{ }^{* * * *} p<0.0001$

a PI3K-independent path-were not affected by the addition of the PI3K inhibitors and retained the intense nuclear Nrf2 immunostaining.

The MTZ-, MEL-, and Trolox-mediated activation of the antioxidant response proteins SOD1 and HO-1 was studied in the presence of Wortmannin, LY294002, and SB216763. Consistent with the effect of the different inhibitors on the nuclear Nrf2 translocation, Fig. 14 depicts representative images of the PI3K-dependence of SOD1 and HO-1 activation and the lack of effect of the
GSK-3 inhibitor, whereas Additional file 3: Figure S3 shows the corresponding quantitative evaluation of the images. The four- to six-fold increments in fluorescence values induced by the presence of MTZ, MEL, and Trolox were brought down to levels not significantly different than untreated control cells in the presence of PI3K inhibitors whereas the inclusion of the GSK-3 inhibitor SB216763 had no effect. As anticipated, the PI3K-independent SFN-mediated activation of $\mathrm{Nrf} 2$ downstream proteins was not affected by the 

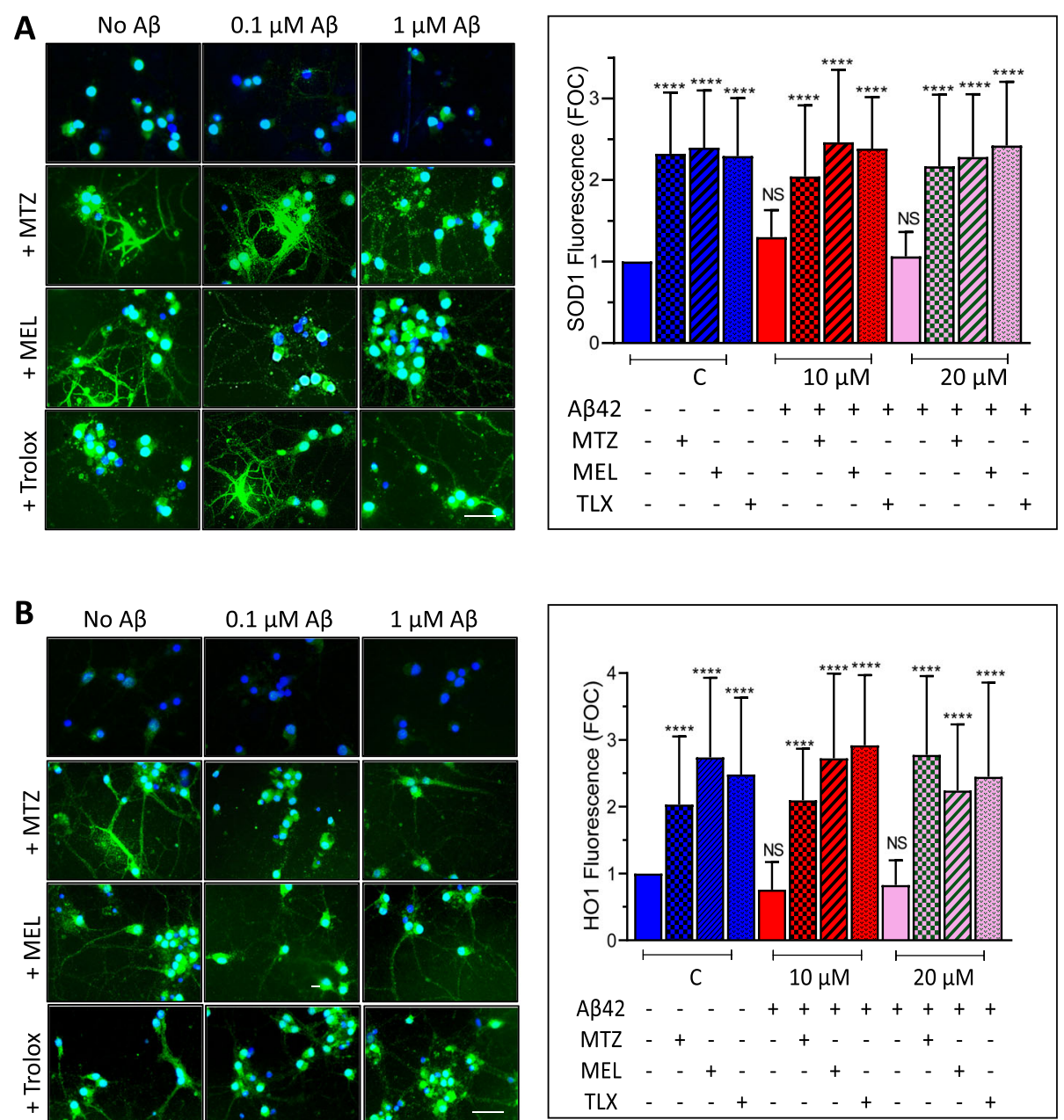

Fig. 10 Translational activation of the downstream Nrf2 targets SOD-1 and HO-1 by methazolamide, melatonin, and Trolox in primary cortical neurons. Cells were treated with the Nrf2 activators MTZ, MEL, and Trolox in the presence/absence of A $342(0-1 \mu \mathrm{M})$ as in Fig. 9. Expression of SOD-1 (a) and HO-1 (b) was detected by immunocytochemical analysis using rabbit polyclonal anti-SOD-1 and mouse monoclonal anti-HO-1 primary antibodies followed by the pertinent Alexa-488 conjugated secondary antibodies. Green fluorescence highlights SOD-1 (a) and HO-1 (b) immunoreactivity; blue fluorescence depicts DAPI nuclear DNA counterstaining. Bar, $25 \mu \mathrm{m}$ in all images. The graphs in $\mathbf{a}$ and $\mathbf{b}$ depict respectively the quantitation of SOD-1 and HO-1 fluorescence signal in 50-100 cells utilizing ImageJ software and expressed in fold of control. Data is represented as mean $\pm S D ;{ }^{* * *} p<0.0001$

Wortmannin and LY294002 inhibitors. Overall, the data indicates that MTZ, MEL, and Trolox activate the cellular antioxidant response via the PI3K/Akt-GSK-3 axis.

\section{Discussion}

The brain accounts for only $\sim 2 \%$ of the total body mass but receives up to $20 \%$ of cardiac output and is responsible for $20-25 \%$ of the body's $\mathrm{O}_{2}$ and glucose consumption, highlighting the high energy requirement essential for the maintenance of its physiological functions [51]. As the brain has limited energy storage capacity, mitochondria are crucial organelles for generating through OXPHOS the levels required to avoid even brief periods of energy deprivation that would result in cell dysfunction and death. These essential organelles-primarily abundant in cells with high energy demands, as neurons-control cell bioenergetics and ROS homeostasis with recent data stressing their critical role in the regulation of the blood-brain barrier permeability and synaptic integrity, actively participating in the underlying mechanisms of learning and memory [52-54].

Dysregulation of mitochondrial downstream pathways in $\mathrm{AD}$ brains has been demonstrated in multiple studies [55-58]. Numerous investigations have illustrated increased generation of free radicals, lipid peroxidation, oxidative DNA, and protein damage in conjunction with decreased ATP production [59-63]. Altered cerebral glucose utilization, a metabolic feature tightly related to mitochondrial function [59] and an invariant $\mathrm{AD}$ 


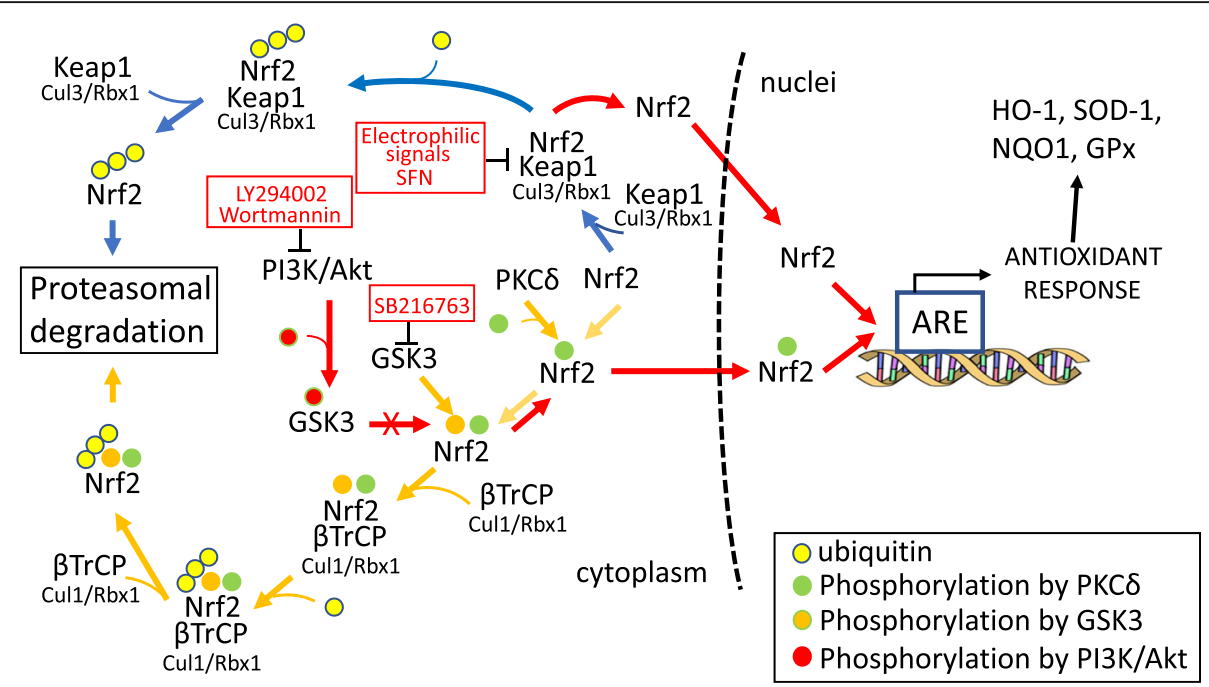

Fig. 11 The main activation pathways of Nrf2. The diagram illustrates the main homeostatic pathways regulating the transcription factor Nrf2 proteosomal degradation and activation through its nuclear translocation. The figure indicates the sites of action of PI3K inhibitors LY294002 and Wortmannin, the GSK-3 inhibitor SB216763, as well as SFN, an electrophilic activator that disrupts the Nrf2-Keap1 complex formation

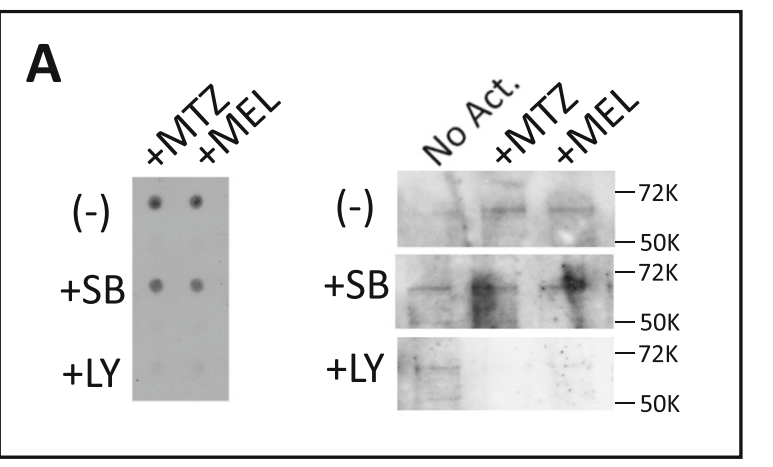

B

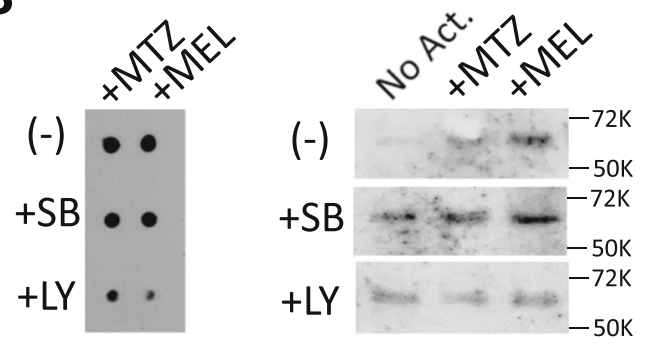

Fig. 12 Assessment of PI3K-mediated Nrf2 activation in SH-SY5Y and primary neurons by dot and Western blot analyses. SH-SY5Y cells and primary cortical neurons were treated with MTZ $(300 \mu \mathrm{M})$ and MEL $(100 \mu \mathrm{M})$ in the presence/absence of the PI3K inhibitor LY294002 and the GSK-3 inhibitor SB216763 (both at $10 \mu \mathrm{M}$ concentration). This was followed by an evaluation of Nrf2 reactivity in nuclear extracts by dot and Western blot analysis following the protocols described in the "Material and methods" section. a SHSY5Y cells. b Primary neurons. In both cases, left panels illustrate the dot blot images and right panels the Western blot detection pathophysiological feature, is in fact increasingly recognized as a critical contributor to disease pathogenesis [64, 65]. Impairment of glucose metabolism, particularly in areas with dense synaptic content, was demonstrated by $\left[{ }^{18} \mathrm{~F}\right]$-fluorodeoxyglucose positron emission tomography $\left(\left[{ }^{18} \mathrm{~F}\right]\right.$ FDG-PET) [66] and magnetic resonance spectroscopy (MRS) [64] approaches. Biochemical analyses have shown decreased activity of key enzymes controlling metabolic flux to the tricarboxylic acid (TCA) cycle-pyruvate dehydrogenase, $\alpha$-ketoglutarate dehydrogenase, and isocitrate dehydrogenase-as well as changes in malic enzyme, a major anaplerotic component in neurons, parameters correlating with cognitive impairment [67-72]. Most of these findings were also recapitulated in different rodent transgenic lines including the widely studied Tg2576 [73-80]. In this model, caspase- 3 activity was found elevated in hippocampal synapsis before amyloid deposition was detectable, causing reduction of spine density in CA1 pyramidal neurons, alterations in glutamatergic synaptic transmission, and deficits in hippocampaldependent contextual fear conditioning [52], all features rescued by pharmacologic inhibition of caspase- 3 and suggestive of the central role of mitochondria in early synaptic dysfunction. Further highlighting mitochondrial dysfunction in this model, proteomic analysis has shown early dysregulation in mitochondrial proteins [81] while metabolomic profiling indicated alterations in energy metabolism [82]. Thus, targeting early synaptic deficits by halting the detrimental effects of oligA $\beta$ on mitochondrial dysfunction and synaptic integrity has emerged as potentially effective-although still elusive-strategies to preserve cognitive function [83]. 


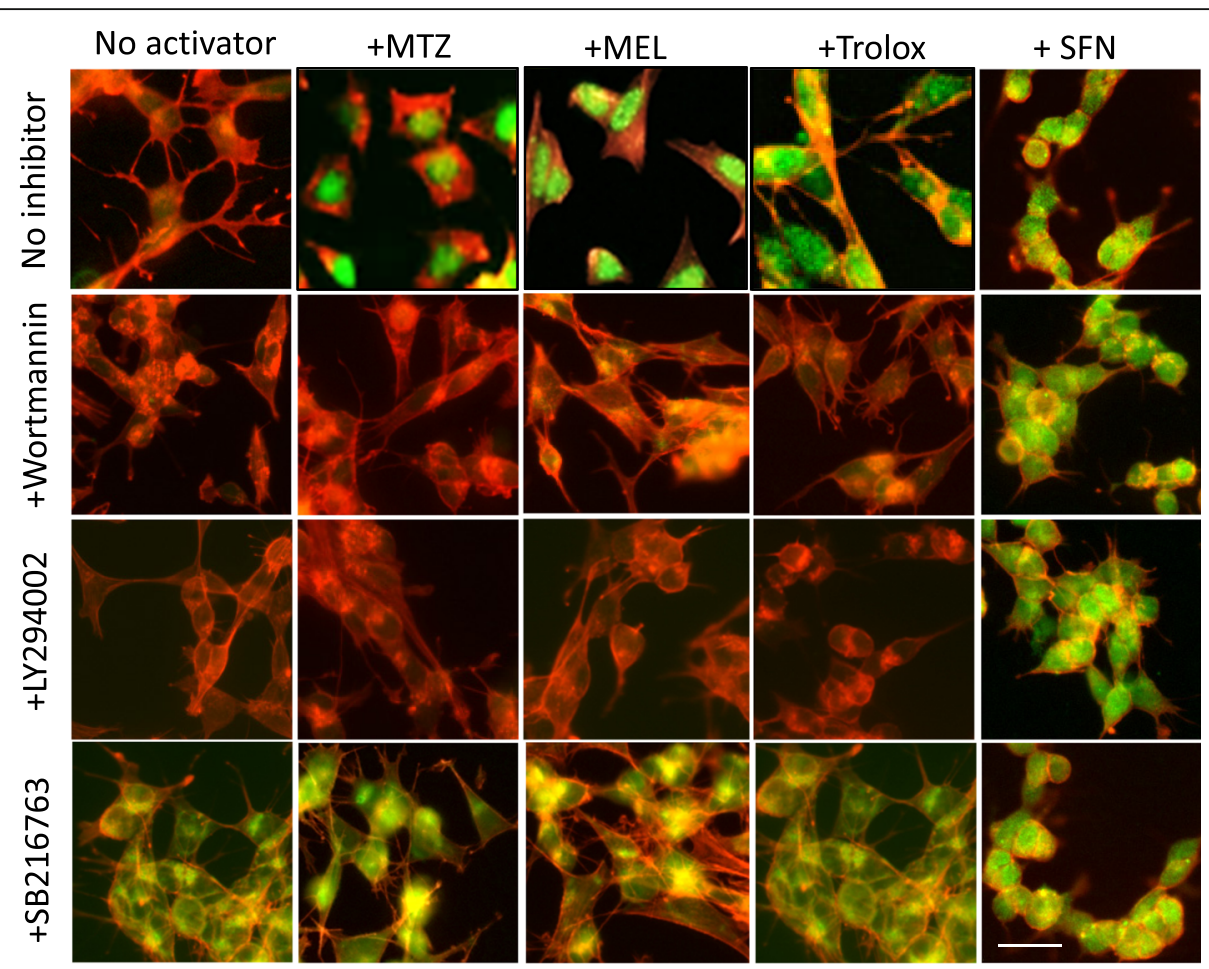

Fig. 13 Methazolamide, melatonin, and Trolox activate Nrf2 through a PI3K-mediated pathway. SH-SY5Y cells were treated with MTZ (300 $\mu M$ ), MEL $(100 \mu M)$, or Trolox $(300 \mu M)$ in the presence of the PI3K inhibitors LY294002 and Wortmannin (10 $\mu$ M each) or the GSK-3 inhibitor SB216763 $(10 \mu \mathrm{M})$. As a control, cells were incubated with SFN $(5 \mu \mathrm{M})$, a compound capable of activating Nrf2 through disruption of its binding to Keap-1, a PI3K-independent pathway. In all cases, Nrf2 expression was evaluated by immunocytochemistry as in Figs. 7 and 8. Green fluorescence highlights Nrf2 nuclear translocation, and red fluorescence depicts actin staining with Alexa 588-conjugated phalloidin. Bar represents $20 \mu \mathrm{m}$ in all images. Quantitation of the nuclear fluorescence signal is shown in Additional file 2: Figure S2

A common feature in the progression toward cell death is the release of cytochrome $\mathrm{c}$ from the mitochondria into the cytoplasm leading to the formation of the apoptosome and downstream activation of terminal caspase-3 [84, 85]. Almost a decade ago, MTZ and MEL were identified as two drugs capable of preventing cytochrome $\mathrm{c}$ release in isolated mitochondria and exhibiting neuroprotective properties in models of ischemic injury and Huntington disease [22, 23]. More recent work from our lab has studied the effect of MTZ on A $\beta$-mediated mitochondrial dysfunction in different cell culture models demonstrating the ability of the compound in protecting cells from the detrimental effect of $A \beta$, preventing the $A \beta$-elicited release of cytochrome $c$ and changes in the organelle membrane potential, and ultimately inhibiting the induction of cell death mechanisms $[7,8,24]$. The work presented herein demonstrate that both MTZ and MEL, as well as the potent ROS scavenger and vitamin $\mathrm{E}$ analog Trolox, not only prevent the formation of oxidative radicals in SH-SY5Y and primary cortical neurons but also protect from the metabolic/ bioenergetic deficits induced by $A \beta$, restoring basal and maximal respiration as well as ATP production to the levels of untreated cells. Whether the protective effect of
MTZ, MEL, and Trolox on the A $\beta$-mediated metabolic/ bioenergetic alterations results from the ROS-scavenging activity of the compounds and reflects the intricate relationship between ROS homeostasis and respiration [86] remains to be determined.

In spite of the comparable protective effect exerted by MTZ, MEL, and Trolox in the neuronal A $\beta$-mediated changes observed in our in vitro paradigm, all three compounds have a strikingly different described primary activity. MTZ, FDA-approved for the local treatment of glaucoma, has been reported to act as a carbonic anhydrase inhibitor and as such modulates the reversible conversion of $\mathrm{CO}_{2}$ to $\mathrm{HCO}^{-}$essential for the anaplerotic replenishing of TCA intermediates and for the regulation of carboxylating enzymes using $\mathrm{CO}_{2}$ as substrate, being among them malic enzyme, propionyl-, methylcrotonyl-, and acetyl-CoA carboxylases the most relevant in neurons [87]. MEL is a pineal gland hormone that regulates circadian rhythms of physiologic activities as sleep [22]. It is a potent antioxidant active in different in vivo systems, including the CNS and at the level of the synapses $[29,88]$ but does not exhibit recognizable carbonic anhydrase inhibitory activity. More recent work has demonstrated a more wide-ranging effect of MEL on 


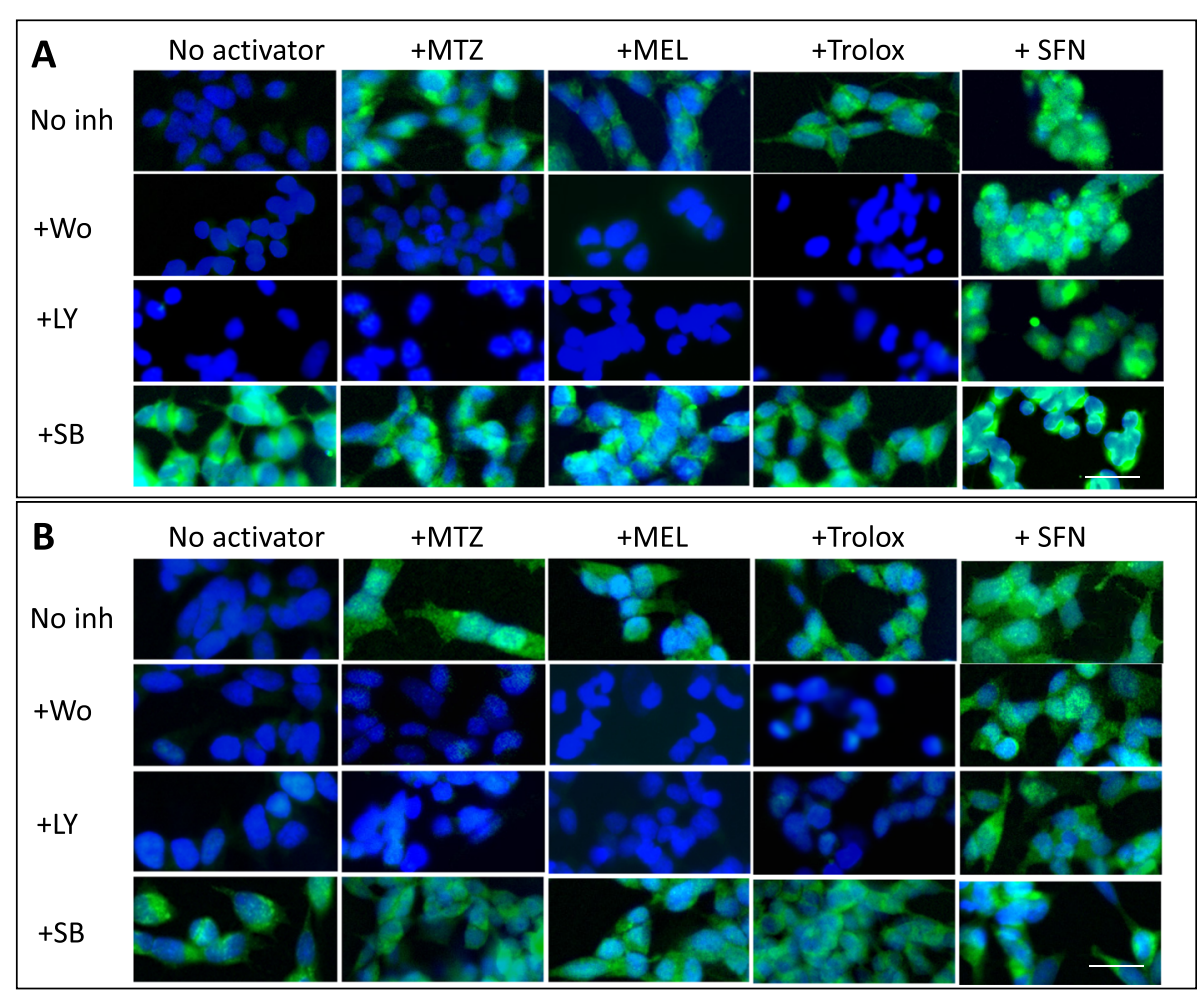

Fig. 14 Methazolamide, melatonin, and Trolox activate Nrf2 downstream antioxidative response proteins SOD-1 and HO-1 through the PI3K axis. SH-SY5Y cells were treated with MTZ, MEL, Trolox, or SFN in the presence of the PI3K inhibitors LY294002 and Wortmannin or the GSK-3 inhibitor SB216763 as in Fig. 13. In all cases, SOD-1 and HO-1 expression was evaluated by immunocytochemistry using the respective primary antibodies followed by Alexa 488-conjugated secondary antibodies. Green fluorescence highlights SOD-1 (a) and HO-1 (b) reactivity; blue fluorescence depicts DAPI nuclear DNA counterstaining. Bar, $25 \mu \mathrm{m}$ in all images. Quantitation of the cytoplasmic SOD-1 and HO-1 fluorescent signals is shown in Additional file 3: Figure S3

mitochondrial activity precluding astrocytic $A \beta-$ mediated mitochondrial depolarization [88] as well as preventing caspase-3-mediated apoptosis and enhancing ATP synthesis under conditions of metabolic- and radiation-mediated stress $[28,89]$. Trolox is a watersoluble vitamin $\mathrm{E}$ analog which due to its high capacity to capture ROS is used as a standard for the evaluation of the antioxidant capacity of other molecules [45]. Through its capacity to quench and react with single oxygen and neutralize free radical species, which indeed surpasses that of vitamin E [90, 91], Trolox has been reported to prevent neurotoxicity induced by $A \beta$ and hydrogen peroxide $[92,93]$.

The dissimilar primary biological activities of MTZ, MEL, and Trolox provide an interesting paradigm to better dissect how potentially converging pathways are involved in the $\mathrm{A} \beta$-induced mitochondrial dysfunction described in the current work. Based on the reports of its downregulation in Alzheimer's patients and transgenic models described below, as well as in its wide role in regulating metabolic pathways compromised in the disease, we focused our attention in the central regulator of the antioxidant response, the nuclear factor erythroid 2-related factor 2 (Nrf2) [49, 50], a redox statedependent transcription factor and key regulator of inducible defense systems [94]. Located in the cytosol with constitutive low levels strictly controlled by the proteasome [95], its degradation is drastically reduced under pathological or stress conditions leading to Nrf2 accumulation and nuclear translocation. Once in the nuclei, Nrf2 binds the antioxidant response elements (AREs), common promoters of endogenous protective genes, among them $\mathrm{NAD}(\mathrm{P}) \mathrm{H}$-quinone oxidoreductase (NQO1), and glutathione-S-transferase (GST), as well as heme-oxygenase 1 (HO-1) and superoxide dismutase 1 (SOD-1) [96] which are studied herein, initiating the transcription and protein expression of the antioxidant genes. The studies reported herein indicate that through Nrf2 activation MTZ, MEL, and Trolox not only counterbalance the A $\beta$-mediated ROS generation but also the concomitant metabolic/bioenergetic changes. Reinforcing the link between Nrf2 activation and restoration of mitochondrial metabolic parameters, it has been shown that canonical Nrf2 activators as the electrophilic agent SFN as well as other natural antioxidants not only counteract $A \beta$-mediated apoptotic and oxidative mechanisms but also protect from amyloid-induced 
alterations in mitochondrial respiration and ATP production both in neuronal cultures and transgenic mouse models [97-102]. In spite of their potential for the development of future therapeutic strategies, the consequences of the prolonged use of Nrf2 activators should be further explored, specially taking into consideration the reported association of Nrf2 exacerbated activation with certain types of cancer [103].

Different mechanisms have been reported as responsible for the activation of Nrf2. Until recently, the prevailing view was that Nrf2 was primarily regulated through the Keap1 (Kelch-like ECH-associated protein 1) pathway. Keap1, as part of the E3 ubiquitin ligase complex together with Cullin 3 and Ring-Box 1, is able to interact with $\mathrm{Nrf} 2$ allowing its ubiquitination and subsequent proteosomal degradation, a mechanism that maintains Nrf2 low endogenous levels [104, 105]. As illustrated in Fig. 11, electrophilic molecules are capable of interfering with this Nrf2 degradation path by chemically modifying specific sensor Cys residues in the Keap1 molecule leading to conformational changes that prevent its binding to Nrf2 and its subsequent proteosomal degradation, ultimately resulting in the nuclear translocation and activation of the transcription factor $[104,106]$. Although Keap1 is the most studied regulator of Nrf2 activity, more recently, the role of another E3ubiquitin ligase adaptor, $\beta$-TrCP $(\beta$-transducing repeatcontaining protein), was described [49]. This mechanism, independent of Keap1 (Fig. 11), is regulated by glycogen synthase kinase 3 (GSK-3) which phosphorylates Nrf2 targeting it for proteosomal degradation upon binding to the multi-protein complex formed by $\beta$-TrCP together with the Skp1 adaptor, Cullin 1, and Rbx1 [107, 108]. Cell signaling pathways such as PI3K/Akt, able to phosphorylate and inactivate GSK-3, inhibit Nrf2 degradation and result in its nuclear translocation and activation [49].

It is known that Nrf2 is compromised by age [109, 110] and downregulated in AD [111], deficits replicated in different animal models $[112,113]$. Notably, our data indicate that $A \beta$ challenge did not translate in a concomitant activation of Nrf2 and its downstream antioxidant response elements in spite of eliciting a severe ROS production in neuronal cells, findings consistent with the Nrf2 downregulation coexisting with the amply documented oxidative stress reported in $\mathrm{AD}[111,114]$. Along this line, it is noteworthy to mention that $A \beta$ has been shown to activate GSK-3 signaling in vitro, a finding consistent with the increased activity of the enzyme observed in AD brains [115]. Thus, it is tempting to speculate that, based on GSK-3 role as a key element in one of the major pathways regulating Nrf2 ubiquitination and proteosomal degradation, A $\beta$-mediated GSK-3 activation may account for the lack of $\mathrm{Nrf} 2$ activation and nuclear translocation even in the presence of the exacerbated $A \beta$-mediated ROS generation reported herein.

The presence of MTZ, MEL, and Trolox-compounds that completely inhibited $A \beta$-mediated ROS generation and restored ATP production-induced the activation and nuclear translocation of Nrf2 in both SH-SY5Y and primary neurons pointing out to a crucial role of the transcription factor in the prevention of $A \beta$-mediated neuronal dysfunction. Whether other protective pathways are additionally targeted by the compounds remains to be investigated. Our work, through the use of different inhibitors affecting Keap- 1 and $\beta$-TrCP degradation pathways, demonstrates that all three $A \beta$ protective compounds, in difference to the electrophilic compound SFN, activate Nrf2 and subsequent downstream antioxidant proteins through the PI3K/GSK-3 axis and not through disruption of the Nrf2-Keap-1 complex. The precise mechanisms by which MTZ, MEL, and Trolox affect PI3K/GSK-3 action remain to be elucidated. In the case of melatonin, limited reports suggest a role for melatonin receptor in the activation of the pathway $[116,117]$, but to our knowledge, no receptor has been described for MTZ. However, irrespective of the underlying mechanisms, the Nrf2 activation and concomitant induction of downstream antioxidative proteins likely account for the protective effect of the compounds on $\mathrm{A} \beta$-mediated dysfunction.

Underscoring the pharmacologic potential of the $A \beta$ protective compounds employed in the current work for future prospective therapeutic strategies, it should be noted that both MTZ and MEL are FDA-approved drugs with well-studied bioavailability, organ distribution, and pharmacokinetics. As it is the case of Trolox, MTZ and MEL have been shown to be well-absorbed and cross the $\mathrm{BBB}[23,118-121]$ and, as a result, have the potential to be active in vivo. Indeed, highlighting the relevance of our work and the potential of antioxidant treatment for neurodegenerative disorders, limited published work indicates that MEL administration preserved age-dependent cognitive impairment in APPPS1 transgenic mice [122] while Trolox protected this transgenic line from its characteristic neuritic alterations [123]. Further studies are needed to completely demonstrate the in vivo efficacy of MTZ, MEL, and Trolox as pharmacologic compounds targeting $A \beta$-mediated alterations and capable of ameliorating oxidative damage, restoring mitochondrial function and metabolic/bioenergetic abnormalities in transgenic models.

\section{Conclusions}

Overall, the data presented herein provide insight into the detrimental effect of $A \beta$ for mitochondrial function and the metabolic/bioenergetic changes that correlate with dysregulation of neuronal activity in AD. The work 
delineates the molecular mechanisms by which MTZ, MEL, and the vitamin $E$ analog Trolox protect from $A \beta$ mediated detrimental alterations and concomitant metabolic changes identifying their common mechanistic activity as Nrf2 activators through the PI3K/GSK-3 axis and validating the relevance of these pathways as targets for pharmacological intervention. Based on the unsuccessful outcome of numerous $\mathrm{AD}$ clinical trialsamong them those aimed at decreasing $A \beta$ levels through diminishing its production or increasing its brain clearance, as well as those protecting from agerelated oxidative stress-it is becoming clearer that targeting only one element of the complex interlinked cellular pathways affected by the disease will not be sufficient. Successful prevention/delay of AD development will more likely require complex strategies encompassing multiple genes and pathways. The findings reported herein suggest that modulation of the PI3K/ Akt path-likely an early event in the disease process leading to both suppression of the stress response and decreased neuronal survival-may constitute attractive targets. The use of small molecule Nrf2 activators may offer additional approaches either as preventive agents or in combination therapies with other treatment options to address the detrimental effects of $A \beta$ on mitochondrial and synaptic function as well as the metabolic/bioenergetic abnormalities encompassing the complex and multifactorial pathways leading to $\mathrm{AD}$ pathogenesis.

\section{Supplementary information}

Supplementary information accompanies this paper at https://doi.org/10. 1186/s13195-019-0578-9.

Additional file 1: Figure S1. Kinetic of cellular oxygen consumption in a Seahorse platform. The graph is a schematic example of real time changes in OCR values using the Cell Mito Stress Assay in a Seahorse metabolic analyzer. The figure depicts the injection time-points of the different modulators of cellular respiration and illustrates the kinetic data analysis employed by Report Generator software to evaluate the fundamental parameters of mitochondrial function: basal respiration, ATP production, proton leak, maximal respiration, spare respiratory capacity, and non-mitochondrial respiration.

Additional file 2: Figure S2. Quantitation of Nrf2 nuclear fluorescence induced by Methazolamide, Melatonin, and Trolox in the presence of PI3Kand GSK-3 inhibitors. Graph depicts the quantitation of Nrf2 nuclear fluorescence signal from images depicted in Figure 13. Fluorescence of at least 400 cells was quantitated utilizing ImageJ software and expressed in fold of control cells. Data is represented as mean \pm SD; ${ }^{* * *}$ indicates $p<0.0001$.

Additional file 3: Figure S3. Quantitation of cytoplasmic SOD-1 and $\mathrm{HO}-1$ fluorescence induced by Methazolamide, Melatonin, and Trolox in the presence of PI3K- and GSK-3 inhibitors. Graphs in Panels A and B depict the quantitation of the cytoplasmic SOD-1 and HO-1fluorescence signal, respectively, of at least 400 cells utilizing ImageJ software and expressed in fold of control. Data is represented as mean \pm SD; ${ }^{* * *}$ indicates $p<0.0001$.

\section{Abbreviations}

AD: Alzheimer's disease; Akt: Protein kinase B; Aß: Amyloid- $\beta$; EM: Electron microscopy; FCCP: p-trifluoro methoxy-carbonyl cyanide phenylhydrazine;
GSK-3: Glycogen synthase kinase 3; Keap1: Kelch-like ECH-associated protein 1; MEL: Melatonin; MTZ: Methazolamide; Nrf2: Nuclear factor erythroidderived 2-like 2; PI3K: Phosphatidylinositol 3-kinase;

RIPA: Radioimmunoprecipitation assay; ROS: Reactive oxygen species; SFN: Sulforaphane; TLX: Trolox; WB: Western blot

\section{Acknowledgements}

Not applicable

\section{Authors' contributions}

$A R$ and JG designed the experimental approach, directed the project, and wrote the manuscript. KS performed the experimental work. KS and AR performed studies in the Seahorse analyzer. KS, AR, and JG analyzed the data. All authors read and approved the final paper.

\section{Funding}

The work was partially supported by the National Institute of Health research grants AG059695, AG051266, and P30CA016087; the BrightFocus Foundation A2015275S; and the Alzheimer's Association ZEN-14-283969.

\section{Availability of data and materials}

The datasets used and/or analyzed during the current study are available from the corresponding authors on reasonable request.

\section{Ethics approval and consent to participate}

Rat primary cortical neuron cultures were prepared in compliance with all international and $\mathrm{NIH}$ guidelines for the care and use of laboratory animals, in accordance with the New York University School of Medicine Institutional Animal Care and Use Committee guidelines.

\section{Consent for publication}

Not applicable

\section{Competing interests}

The authors declare that they have no competing interests.

\section{Author details}

${ }^{1}$ Department of Pathology, New York University School of Medicine, 550 First Avenue, New York, NY 10016, USA. ²Department of Psychiatry, New York University School of Medicine, 550 First Avenue, New York, NY 10016, USA.

Received: 16 September 2019 Accepted: 30 December 2019 Published online: 13 January 2020

\section{References}

1. Rostagno A, Holton JL, Lashley T, Revesz T, Ghiso J. Cerebral amyloidosis: amyloid subunits, mutants and phenotypes. Cell Mol Life Sci. 2010;67:581-600.

2. Holtzman DM, Morris JC, Goate AM. Alzheimer's disease: the challenge of the second century. Sci Transl Med. 2011;3:77sr1.

3. Walsh DM, Selkoe DJ. A beta oligomers - a decade of discovery. $J$ Neurochem. 2007:101:1172-84.

4. Caughey B, Lansbury PTJ. Protofibrils, pores, fibrils, and neurodegeneration: separating the responsible protein aggregates from the inocent bystanders. Annu Rev Neurosci. 2003;26:267-98.

5. Moreira PI, Carvalho C, Zhu X, Smith MA, Perry G. Mitochondrial dysfunction is a trigger of Alzheimer's disease pathophysiology. Biochim Biophys Acta. 2010;1802:2-10.

6. Nunomura A, Perry G, Aliev G, Hirai K, Takeda A, Balraj EK, Jones PK, Ghanbari H, Wataya T, Shimohama S, Chiba S, Atwood CS, Petersen RB, Smith MA. Oxidative damage is the earliest event in Alzheimer disease. J Neuropathol Exp Neurol. 2001;60:759-67.

7. Fossati S, Ghiso J, Rostagno A. Insights into caspase-mediated apoptotic pathways induced by amyloid- $\beta$ in cerebral microvascular endothelial cells. Neurodegener Dis. 2012;10:324-8.

8. Fossati S, Cam J, Meyerson J, Mezhericher E, Romero IA, Couraud P-O, Weksler B, Ghiso J, Rostagno A. Differential activation of mitochondrial apoptotic pathways by vasculotropic amyloid- $\beta$ variants in cells composing the cerebral vessel walls. FASEB J. 2010;24:229-41.

9. Viana RJ, Nunes AF, Castro RE, Ramalho RM, Meyerson J, Fossati S, Ghiso J, Rostagno A, Rodrigues CM. Tauroursodeoxycholic acid prevents E22Q 
Alzheimer's A $\beta$ toxicity in human cerebral endothelial cells. Cell Mol Life Sci. 2009:66:1094-104.

10. Perez-Cruz C, Nolte MW, van Gaalen MM, Rustay NR, Termont A, Tanghe A, Kirchhoff F, Ebert U. Reduced spine density in specific regions of CA1 pyramidal neurons in two transgenic mouse models of Alzheimer's disease. J Neurosci. 2011;31:3926-34.

11. Hsu MJ, Sheu JR, Lin CH, Shen MY, Hsu CY. Mitochondrial mechanisms in amyloid beta peptide-induced cerebrovascular degeneration. Biochim Biophys Acta. 2010;1800;290-6.

12. Du H, Guo L, Yan S. Synaptic mitochondrial pathology in Alzheimer's disease. Antioxid Redox Signal. 2012;16:1467-75.

13. Klein WL. Synaptic targeting by A oligomers (ADDLS) as a basis for memory loss in early Alzheimer's disease. Alzheimers Dement. 2006;2: 43-55.

14. Solito R, Corti F, Fossati S, Mezhericher E, Donnini S, Ghiso J, Giachetti A, Rostagno A, Ziche M. Dutch and Arctic mutant peptides of beta amyloid(140) differentially affect the FGF-2 pathway in brain endothelium. Exp Cell Res. 2009;315:385-95.

15. Olszewska A, Szewczyk A. Mitochondria as a pharmacological target: magnum overview. IUBMB Life. 2013;65:273-81.

16. Wu CC, Bratton SB. Regulation of the intrinsic apoptosis pathway by reactive oxygen species. Antioxid Redox Signal. 2013;19:546-58.

17. Papandreou MA, Kanakis CD, Polissiou MG, Efthimiopoulos S, Cordopatis $P$, Margarity M, Lamari FN. Inhibitory activity on amyloid-beta aggregation and antioxidant properties of Crocus sativus stigmas extract and its crocin constituents. J Agric Food Chem. 2006;54:8762-8.

18. Ochiai T, Shimeno H, Mishima K, Iwasaki K, Fujiwara M, Tanaka H, Shoyama Y, Toda A, Eyanagi R, Soeda S. Protective effects of carotenoids from saffron on neuronal injury in vitro and in vivo. Biochim Biophys Acta. 2007;1770: 578-84.

19. Yu W, Fu YC, Wang W. Cellular and molecular effects of resveratrol in health and disease. J Cell Biochem. 2012;113:752-9.

20. Andersen JK. Oxidative stress in neurodegeneration: cause or consequence? Nat Med. 2004;10:S18-25.

21. Pasinetti GM, Wang J, Ho L, Zhao W, Dubner L. Roles of resveratrol and other grape-derived polyphenols in Alzheimer's disease prevention and treatment. Biochim Biophys Acta. 2015;1852:1202-8.

22. Wang X, Figueroa BE, Stavrovskaya IG, Zhang Y, Sirianni AC, Zhu S, Day AL, Kristal BS, Friedlander RM. Methazolamide and melatonin inhibit mitochondrial cytochrome $\mathrm{C}$ release and are neuroprotective in experimental models of ischemic injury. Stroke. 2009;40:1877-85.

23. Wang X, Zhu S, Pei Z, Drozda M, Stavrovskaya IG, Del Signore SJ, Cormier K, Shimony EM, Wang H, Ferrante RJ, Kristal BS, Friedlander RM. Inhibitors of cytochrome c release with therapeutic potential for Huntington's disease. J Neurosci. 2008;28:9473-85.

24. Fossati S, Giannoni P, Solesio ME, Cocklin SL, Cabrera E, Ghiso J, Rostagno A. The carbonic anhydrase inhibitor methazolamide prevents amyloid betainduced mitochondrial dysfunction and caspase activation protecting neuronal and glial cells in vitro and in the mouse brain. Neurobiol Dis. 2016; 86:29-40.

25. Pappolla MA, Chyan YJ, Poeggeler B, Frangione B, Wilson G, Ghiso J, Reiter RJ. An assessment of the antioxidant and the antiamyloidogenic properties of melatonin: implications for Alzheimer's disease. J Neural Transm. 2000 107:203-31.

26. Chyan YJ, Poeggeler B, Omar RA, Chain DG, Frangione B, Ghiso J, Pappolla MA. Potent neuroprotective properties against the Alzheimer beta-amyloid by an endogenous melatonin-related indole structure, indole-3-propionic acid. J Biol Chem. 1999;274:21937-42.

27. Fischer TW, Zmijewski MA, Wortsman J, Slominski A. Melatonin maintains mitochondrial membrane potential and attenuates activation of initiator (casp-9) and effector caspases (casp-3/casp-7) and PARP in UVR-exposed HaCaT keratinocytes. J Pineal Res. 2008:44:397-407.

28. Baydas G, Reiter RJ, Akbulut M, Tuzcu M, Tamer S. Melatonin inhibits neural apoptosis induced by homocysteine in hippocampus of rats via inhibition of cytochrome c translocation and caspase-3 activation and by regulating pro- and anti-apoptotic protein levels. Neuroscience. 2005;135:879-86.

29. Millán-Plano S, Piedrafita E, Miana-Mena FJ, Fuentes-Broto L, MartínezBallarín E, López-Pingarrón L, Sáenz MA, García JJ. Melatonin and structurally-related compounds protect synaptosomal membranes from free radical damage. Int J Mol Sci. 2010;11:312-28.
30. Stine WBJ, Dahlgren KN, Krafft GA, LaDu MJ. In vitro characterization of conditions for amyloid- $\beta$ peptide oligomerization and fibrillogenesis. J Biol Chem. 2003;278:11612-22.

31. Fossati S, Todd K, Sotolongo K, Ghiso J, Rostagno A. Differential contribution of isoaspartate post-translational modifications to the fibrillization and toxic properties of amyloid $\beta$ and the Asn23 lowa mutation. Biochem J. 2013:456: $347-60$.

32. Restituito S, Khatri L, Ninan I, Mathews P, Liu S, Weinberg RJ, Ziff EB. Synaptic autoregulation by metalloproteases and $\gamma$-secretase. J Neurosci. 2011;31:12083-93.

33. Kayed R, Head E, Thompson JL, McIntire TM, Milton SC, Cotman CW, Glabe CG. Common structure of soluble amyloid oligomers implies common mechanism of pathogenesis. Science. 2003;300:486-9.

34. Cabrera E, Mathews P, Mezhericher E, Beach TG, Deng J, Neubert TA, Rostagno A, Ghiso J. A $\beta$ truncated species: implications for brain clearance mechanisms and amyloid plaque deposition. Biochim Biophys Acta. 2018; 1864:208-25.

35. Todd K, Fossati S, Ghiso J, Rostagno A. Mitochondrial dysfunction induced by a post-translationally modified amyloid linked to a familial mutation in an alternative model of neurodegeneration. Biochim Biophys Acta. 2014; 1842:2457-67.

36. Todd K, Ghiso J, Rostagno A. Oxidative stress and mitochondria-mediated cell death mechanisms triggered by the familial Danish dementia ADan amyloid. Neurobiol Dis. 2015;85:130-43.

37. Laird MD, Clerc P, Polster BM, Fiskum G. Augmentation of normal and glutamate-impaired neuronal respiratory capacity by exogenous alternative biofuels. Transl Stroke Res. 2013;4:643-51.

38. Raspotnig G, Fauler G, Jantscher A, Windischhofer W, Schachl K, Leis HJ. Colorimetric determination of cell numbers by Janus green staining. Anal Biochem. 1999:275:74-83.

39. Agostini M, Romeo F, Inoue S, Niklison-Chirou MV, Elia AJ, Dinsdale D, Morone N, Knight RA, Mak TW, Melino G. Metabolic reprogramming during neuronal differentiation. Cell Death Differ. 2016;23:1502-14.

40. Cocco S, Secondo A, Del Viscovo A, Procaccini C, Formisano L, Franco C, Esposito A, Scorziello A, Matarese G, Di Renzo G, Canzoniero LM. Polychlorinated biphenyls induce mitochondrial dysfunction in SH-SY5Y neuroblastoma cells. PLoS One. 2015;10:e0129481.

41. Brand MD, Nicholls DG. Assessing mitochondrial dysfunction in cells. Biochem J. 2011;435:297-312.

42. Deshpande A, Mina E, Glabe C, Busciglio J. Different conformations of amyloid $\beta$ induce neurotoxicity by distinct mechanisms in human cortical neurons. J Neurosci. 2006;26:6011-8.

43. Matsubara E, Bryant-Thomas T, Pacheco Quinto J, Henry TL, Poeggeler B, Herbert D, Cruz-Sanchez F, Chyan YJ, Smith MA, Perry G, Shoji M, Abe K, Leone A, Grundke-Ikbal I, Wilson GL, Ghiso J, Williams C, Refolo LM, Pappolla MA, Chain DG, Neria E. Melatonin increases survival and inhibits oxidative and amyloid pathology in a transgenic model of Alzheimer's disease. J Neurochem. 2003;85:1101-8.

44. Pappolla MA, Chyan YJ, Poeggeler B, Bozner P, Ghiso J, LeDoux SP, Wilson $\mathrm{GL}$. Alzheimer beta protein mediated oxidative damage of mitochondrial DNA: prevention by melatonin. J Pineal Res. 1999:27:226-9.

45. Mickle DA, Weisel RD. Future directions of vitamin $\mathrm{E}$ and its analogues in minimizing myocardial ischemia-reperfusion injury. Can J Cardiol. 1993;9:89-93.

46. Messier EM, Bahmed K, Tuder RM, Chu HW, Bowler RP, Kosmider B. Trolox contributes to Nrf2-mediated protection of human and murine primary alveolar type II cells from injury by cigarette smoke. Cell Death Dis. 2013;4:e573.

47. Andreyev AY, Kushnareva YE, Starkov AA. Mitochondrial metabolism of reactive oxygen species. Biochemistry Biokhimiia. 2005;70:200-14.

48. Giordano S, Darley-Usmar V, Zhang J. Autophagy as an essential cellular antioxidant pathway in neurodegenerative disease. Redox Biol. 2014;2:82-90.

49. Hayes JD, Dinkova-Kostova AT. The Nrf2 regulatory network provides an interface between redox and intermediary metabolism. Trends Biochem Sci. 2014:39:199-218.

50. Holmström KM, Baird L, Zhang Y, Hargreaves I, Chalasani A, Land JM, Stanyer L, Yamamoto M, Dinkova-Kostova AT, Abramov AY. Nrf2 impacts cellular bioenergetics by controlling substrate availability for mitochondrial respiration. Biol Open. 2013;2:761-70.

51. Carvalho C, Correia SC, Santos RX, Cardoso S, Moreira PI, Clark TA, Zhu X, Smith MA, Perry G. Role of mitochondrial-mediated signaling pathways in Alzheimer disease and hypoxia. J Bioenerg Biomembr. 2009;41:433-40. 
52. D'Amelio M, Cavallucci V, Middei S, Marchetti C, Pacioni S, Ferri A, Diamantini A, De Zio D, Carrara P, Battistini L, Moreno S, Bacci A, Ammassari-Teule M, Marie H, Cecconi F. Caspase-3 triggers early synaptic dysfunction in a mouse model of Alzheimer's disease. Nat Neurosci. 2011; 14:69-76.

53. D'Amelio M, Cavallucci V, Cecconi F. Neuronal caspase-3 signaling: not only cell death. Cell Death Differ. 2010;17:1104-14.

54. Moreira PI, Zhu X, Wang X, Lee HG, Nunomura A, Petersen RB, Perry G, Smith MA. Mitochondria: a therapeutic target in neurodegeneration. Biochim Biophys Acta. 1802;2010:212-20.

55. Folin M, Baiguera S, Fioravanzo L, Conconi MT, Grandi C, Nussdorfer GG, Parnigotto PP. Caspase-8 activation and oxidative stress are involved in the cytotoxic effect of beta-amyloid on rat brain microvascular endothelial cells. Int J Mol Med. 2006;17:431-5.

56. Rohn TT, Head E, Nesse WH, Cotman CW, Cribbs DH. Activation of caspase8 in the Alzheimer's disease brain. Neurobiol Dis. 2001;8:1006-16.

57. Robinson RA, Lange MB, Sultana R, Galvan V, Fombonne J, Gorostiza O, Zhang J, Warrier G, Cai J, Pierce WM, Bredesen DE, Butterfield DA. Differential expression and redox proteomics analyses of an Alzheime disease transgenic mouse model: effects of the amyloid- $\beta$ peptide of amyloid precursor protein. Neuroscience. 2011;17:207-22

58. Ma T, Hoeffer CA, Wong H, Massaad CA, Zhou P, ladecola C, Murphy MP, Pautler RG, Klann E. Amyloid $\beta$-induced impairments in hippocampal synaptic plasticity are rescued by decreasing mitochondrial superoxide. $J$ Neurosci. 2011;31:5589-95.

59. Reddy PH, Tripathi R, Troung Q, Tirumala K, Reddy TP, Anekonda V, Shirendeb UP, Calkins MJ, Reddy AP, Mao P, Manczak M. Abnormal mitochondrial dynamics and synaptic degeneration as early events in Alzheimer's disease: implications to mitochondria-targeted antioxidant therapeutics. Biochim Biophys Acta. 2012;1822:639-49.

60. Maurer I, Zierz S, Möller HJ. A selective defect of cytochrome c oxidase is present in brain of Alzheimer disease patients. Neurobiol Aging. 2000;21:455-62

61. Devi L, Prabhu BM, Galati DF, Avadhani NG, Anandatheerthavarada HK. Accumulation of amyloid precursor protein in the mitochondrial import channels of human Alzheimer's disease brain is associated with mitochondrial dysfunction. J Neurosci. 2006;26:9057-68.

62. Manczak M, Park BS, Jung Y, Reddy PH. Differential expression of oxidative phosphorylation genes in patients with Alzheimer's disease: implications for early mitochondrial dysfunction and oxidative damage. NeuroMolecular Med. 2004;5:147-62.

63. Butterfield DA, Drake J, Pocernich C, Castegna A. Evidence of oxidative damage in Alzheimer's disease brain: central role for amyloid beta-peptide. Trends Mol Med. 2001;7:548-54.

64. Chen Z, Zhong C. Decoding Alzheimer's disease from perturbed cerebral glucose metabolism: implications for diagnostic and therapeutic strategies. Prog Neurobiol. 2013;108:21-43.

65. Harris RA, Tindale L, Cumming RC. Age-dependent metabolic dysregulation in cancer and Alzheimer's disease. Biogerontology. 2014;15:559-77.

66. Marcus C, Mena E, Subramaniam RM. Brain PET in the diagnosis of Alzheimer's disease. Clin Nucl Med. 2014;39:e413-e26.

67. Perry EK, Perry RH, Tomlinson BE, Blessed G, Gibson PH. Coenzyme Aacetylating enzymes in Alzheimer's disease: possible cholinergic 'compartment' of pyruvate dehydrogenase. Neurosci Lett. 1980;18:105-10.

68. Sorbi S, Bird ED, Blass JP. Decreased pyruvate dehydrogenase complex activity in Huntington and Alzheimer brain. Ann Neurol. 1983;13:72-8.

69. Butterworth RF, Besnard AM. Thiamine-dependent enzyme changes in temporal cortex of patients with Alzheimer's disease. Metab Brain Dis. 1990;5: 179-84.

70. Gibson GE, Sheu KF, Blass JP. Abnormalities of mitochondrial enzymes in Alzheimer disease. J Neural Transm. 1998;105:855-70.

71. Mastrogiacoma F, Lindsay JG, Bettendorff L, Rice J, Kish SJ. Brain protein and alpha-ketoglutarate dehydrogenase complex activity in Alzheimer's disease. Ann Neurol. 1996:39:592-8.

72. Bubber P, Haroutunian V, Fisch G, Blass JP, Gibson GE. Mitochondria abnormalities in Alzheimer brain: mechanistic implications. Ann Neurol. 2005:57:695-703.

73. Reddy PH, McWeeney S, Park BS, Manczak M, Gutala RV, Partovi D, Jung Y, Yau V, Searles R, Mori M, Quinn J. Gene expression profiles of transcripts in amyloid precursor protein transgenic mice: up-regulation of mitochondrial metabolism and apoptotic genes is an early cellular change in Alzheimer's disease. Hum Molec Genet. 2004;13:1225-40.
74. Eckert A, Hauptmann S, Scherping I, Rhein V, Müller-Spahn F, Götz J, Müller WE. Soluble beta-amyloid leads to mitochondrial defects in amyloid precursor protein and tau transgenic mice. Neurodegener Dis. 2008;5:157-9.

75. Rhein V, Song X, Wiesner A, Ittner LM, Baysang G, Meier F, Ozmen L, Bluethmann H, Dröse S, Brandt U, Savaskan E, Czech C, Götz J, Eckert A. Amyloid-beta and tau synergistically impair the oxidative phosphorylation system in triple transgenic Alzheimer's disease mice. Proc Natl Acad Sci U S A. 2009;106:20057-62.

76. Resende R, Moreira PI, Proença T, Deshpande A, Busciglio J, Pereira C, Oliveira CR. Brain oxidative stress in a triple-transgenic mouse model of Alzheimer disease. Free Radic Biol Med. 2008:44:2051-7.

77. Yao J, Irwin RW, Zhao L, Nilsen J, Hamilton RT, Brinton RD. Mitochondrial bioenergetic deficit precedes Alzheimer's pathology in female mouse model of Alzheimer's disease. Proc Natl Acad Sci U S A. 2009;106:14670-5.

78. Dragicevic N, Mamcarz M, Zhu Y, Buzzeo R, Tan J, Arendash GW, Bradshaw PC. Mitochondrial amyloid-beta levels are associated with the extent of mitochondrial dysfunction in different brain regions and the degree of cognitive impairment in Alzheimer's transgenic mice. J Alzheimers Dis. 2010; 20:S535-S50.

79. Du H, Guo L, Yan S, Sosunov AA, McKhann GM, Yan SS. Early deficits in synaptic mitochondria in an Alzheimer's disease mouse model. Proc Natl Acad Sci U S A. 2010;107:18670-5.

80. Martino Adami PV, Quijano C, Magnani N, Galeano P, Evelson P, Cassina A, Do Carmo S, Leal MC, Castaño EM, Cuello AC, Morelli L. Synaptosomal bioenergetic defects are associated with cognitive impairment in a transgenic rat model of early Alzheimer's disease. J Cereb Blood Flow Metab. 2017;37:69-84.

81. Cuadrado-Tejedor M, Cabodevilla JF, Zamarbide M, Gómez-Isla T, Franco R, Perez-Mediavilla A. Age-related mitochondrial alterations without neuronal loss in the hippocampus of a transgenic model of Alzheimer's disease. Curr Alzheimer Res. 2013;10:390-405.

82. Trushina E, Nemutlu E, Zhang S, Christensen T, Camp J, Mesa J, Siddiqui A, Tamura Y, Sesaki H, Wengenack TM, Dzeja PP, Poduslo JF. Defects in mitochondrial dynamics and metabolomic signatures of evolving energetic stress in mouse models of familial Alzheimer's disease. PLoS One. 2012;7: e32737.

83. Nimmrich V, Ebert U. Is Alzheimer's disease a result of presynaptic failure? Synaptic dysfunctions induced by oligomeric beta-amyloid. Rev Neurosci. 2009;20:1-12

84. Li P, Nijhawan D, Budihardjo I, Srinivasula SM, Ahmad M, Alnemri ES, Wang X. Cytochrome $\mathrm{c}$ and dATP-dependent formation of Apaf-1/caspase-9 complex initiates an apoptotic protease cascade. Cell. 1997;91:479-89.

85. Zou H, Henzel WJ, Liu X, Lutschg A, Wang X. Apaf-1, a human protein homologous to C. elegans CED-4, participates in cytochrome c-dependent activation of caspase-3. Cell. 1997:90:405-13.

86. Cortassa S, O'Rourke B, Aon MA. Redox-optimized ROS balance and the relationship between mitochondrial respiration and ROS. Biochim Biophys Acta. 1837;2014:287-95.

87. Hassel B. Carboxylation and anaplerosis in neurons and glia. Mol Neurobiol. 2000;22:21-40.

88. Ionov M, Burchell V, Klajnert B, Bryszewska M, Abramov AY. Mechanism of neuroprotection of melatonin against beta-amyloid neurotoxicity. Neuroscience. 2011;180:229-37.

89. Kleszczyński K, Zillikens D, Fischer TW. Melatonin enhances mitochondrial ATP synthesis, reduces reactive oxygen species formation, and mediates translocation of the nuclear erythroid 2-related factor 2 resulting in activation of phase-2 antioxidant enzymes ( $\mathrm{Y}$-GCS, HO-1, NQO1) in ultraviolet radiation-treated normal human epidermal keratinocytes (NHEK). J Pineal Res. 2016;61:187-97.

90. Brigelius-Flohé R, Traber MG. Vitamin E: function and metabolism. FASEB J. 1999;13:1145-55.

91. Satoh K, Kadofuku T, Sakagami H. Effect of Trolox, a synthetic analog of alpha-tocopherol, on cytotoxicity induced by UV irradiation and antioxidants. Anticancer Res. 1997;17:2459-63.

92. Teponnou GAK, Joubert J, Malan SF. Tacrine, Trolox and tryptoline as lead compounds for the design and synthesis of multi-target agents for Alzheimer's disease therapy. Open Med Chem J. 2017;11:24-37.

93. Quintanilla RA, Muñoz FJ, Metcalfe MJ, Hitschfeld M, Olivares G, Godoy JA, Inestrosa NC. Trolox and 17beta-estradiol protect against amyloid betapeptide neurotoxicity by a mechanism that involves modulation of the Wnt signaling pathway. J Biol Chem. 2005;280:11615-25. 
94. Sandberg M, Patil J, D'Angelo B, Weber SG, Mallard C. NRF2-regulation in brain health and disease: implication of cerebral inflammation. Neuropharmacol. 2014;79:298-306.

95. Kang MI, Kobayashi A, Wakabayashi N, Kim SG, Yamamoto M. Scaffolding of Keap1 to the actin cytoskeleton controls the function of Nrf2 as key regulator of cytoprotective phase 2 genes. Proc Natl Acad Sci U S A. 2004; 101:2046-51.

96. Lee JM, Calkins MJ, Chan K, Kan YW, Johnson JA. Identification of the NF-E2related factor-2-dependent genes conferring protection against oxidative stress in primary cortical astrocytes using oligonucleotide microarray analysis. J Biol Chem. 2003;278:12029-38.

97. Lee C, Park GH, Lee SR, Jang JH. Attenuation of $\beta$-amyloid-induced oxidative cell death by sulforaphane via activation of NF-E2-related factor 2. Oxidative Med Cell Longev. 2013;2013:313510

98. Liu M, Bai X, Yu S, Zhao W, Qiao J, Liu Y, Zhao D, Wang J, Wang S. Ginsenoside Re inhibits ROS/ASK-1 dependent mitochondrial apoptosis pathway and activation of Nrf2-antioxidant response in beta-amyloidchallenged SH-SY5Y cells. Molecules. 2019;24:pii E2687.

99. Wang Y, Miao Y, Mir AZ, Cheng L, Wang L, Zhao L, Cui Q, Zhao W, Wang H. Inhibition of beta-amyloid-induced neurotoxicity by pinocembrin through Nrf2/HO-1 pathway in SH-SY5Y cells. J Neurol Sci. 2016:368:223-30.

100. Zhang R, Miao QW, Zhu CX, Zhao Y, Liu L, Yang J, An L. Sulforaphane ameliorates neurobehavioral deficits and protects the brain from amyloid $\beta$ deposits and peroxidation in mice with Alzheimer-like lesions. Am J Alzheimers Dis Other Dement. 2015;30:183-91.

101. Gray NE, Zweig JA, Caruso M, Zhu JY, Wright KM, Quinn JF, Soumyanath A. Centella asiatica attenuates hippocampal mitochondrial dysfunction and improves memory and executive function in $\beta$-amyloid overexpressing mice. Mol Cell Neurosci. 2018;93:1-9.

102. Gray NE, Zweig JA, Matthews DG, Caruso M, Quinn JF, Soumyanath A. Centella asiatica attenuates mitochondrial dysfunction and oxidative stress in A $\beta$-exposed hippocampal neurons. Oxidative Med Cell Longev. 2017;2017:7023091.

103. Cloer EW, Goldfarb D, Schrank TP, Weissman BE, Major MB. NRF2 activation in cancer: from DNA to protein. Cancer Res. 2019;79:889-98.

104. Esteras N, Dinkova-Kostova AT, Abramov AY. Nrf2 activation in the treatment of neurodegenerative diseases: a focus on its role in mitochondrial bioenergetics and function. Biol Chem. 2016;397:383-400.

105. Cullinan SB, Gordan JD, Jin J, Harper JW, Diehl JA. The Keap1-BTB protein is an adaptor that bridges Nrf2 to a Cul3-based E3 ligase: oxidative stress sensing by a Cul3-Keap1 ligase. Mol Cell Biol. 2004;24:8477-86.

106. Kobayashi A, Kang MI, Okawa H, Ohtsuji M, Zenke Y, Chiba T, Igarashi K, Yamamoto M. Oxidative stress sensor Keap1 functions as an adaptor for Cul3-based E3 ligase to regulate proteasomal degradation of Nrf2. Mol Cell Biol. 2004;24:7130-9.

107. Rada P, Rojo Al, Evrard-Todeschi N, Innamorato NG, Cotte A, Jaworski T, Tobón-Velasco JC, Devijver H, García-Mayoral MF, Van Leuven F, Hayes JD, Bertho G, Cuadrado A. Structural and functional characterization of Nrf2 degradation by the glycogen synthase kinase 3/ $\beta$-TrCP axis. Mol Cell Biol. 2012:32:3486-99.

108. Chowdhry S, Zhang Y, McMahon M, Sutherland C, Cuadrado A, Hayes JD. Nrf2 is controlled by two distinct $\beta-\operatorname{TrCP}$ recognition motifs in its Neh6 domain, one of which can be modulated by GSK-3 activity. Oncogene. 2013:32:3765-81.

109. van Muiswinkel FL, Kuiperij HB. The Nrf2-ARE signalling pathway: promising drug target to combat oxidative stress in neurodegenerative disorders. Curr Drug Targets CNS Neurol Disord. 2005;4:267-81.

110. McBean GJ, López MG, Wallner FK. Redox-based therapeutics in neurodegenerative disease. Br J Pharmacol. 2017;174:1750-70.

111. Ramsey CP, Glass CA, Montgomery MB, Lindl KA, Ritson GP, Chia LA, Hamilton RL, Chu CT, Jordan-Sciutto KL. Expression of Nrf2 in neurodegenerative diseases. J Neuropathol Exp Neurol. 2007;66:75-85.

112. Yu L, Wang $S$, Chen $X$, Yang $H$, Li X, Xu Y, Zhu X. Orientin alleviates cognitive deficits and oxidative stress in A 1-42-induced mouse model of Alzheimer's disease. Life Sci. 2015;121:104-9.

113. Hong $Y$, An Z. Hesperidin attenuates learning and memory deficits in APP/ PS1 mice through activation of Akt/Nrf2 signaling and inhibition of RAGE/ NF-kB signaling. Arch Pharm Res. 2018;41:655-63.

114. Smith MA, Perry G, Richey PL, Sayre LM, Anderson VE, Beal MF, Kowall N. Oxidative damage in Alzheimer's. Nature. 1996;382:120-1.

115. Llorens-Martín M, Jurado J, Hernández F, Avila J. GSK-3ß, a pivotal kinase in Alzheimer disease. Front Mol Neurosci. 2014;7:46.
116. Ali T, Kim MO. Melatonin ameliorates amyloid beta-induced memory deficits, tau hyperphosphorylation and neurodegeneration via PI3/Akt/GSK$3 \beta$ pathway in the mouse hippocampus. J Pineal Res. 2015;59:47-59.

117. Kong PJ, Byun JS, Lim SY, Lee JJ, Hong SJ, Kwon KJ, Kim SS. Melatonin induces Akt phosphorylation through melatonin receptor- and PI3Kdependent pathways in primary astrocytes. Korean J Physiol Pharmacol. 2008;12:37-41.

118. Wada M, Ikeda R, Fuchigami Y, Koyama H, Ohkawara S, Kawakami S, Kuroda N, Nakashima K. Quantitative and antioxidative behavior of Trolox in rats' blood and brain by HPLC-UV and SMFIA-CL methods. Luminescence. 2016; 31:414-8.

119. Li M, Wang W, Mai H, Zhang X, Wang J, Gao Y, Wang Y, Deng G, Gao L, Zhou S, Chen Q, Wang X. Methazolamide improves neurological behavior by inhibition of neuron apoptosis in subarachnoid hemorrhage mice. Sci Rep. 2016:6:35055

120. Tan DX. Melatonin and brain. Curr Neuropharmacol. 2010;8:161.

121. Harpsøe NG, Andersen LP, Gögenur I, Rosenberg J. Clinical pharmacokinetics of melatonin: a systematic review. Eur J Clin Pharmacol. 2015;71:901-19.

122. Olcese JM, Cao C, Mori T, Mamcarz MB, Maxwell A, Runfeldt MJ, Wang L, Zhang C, Lin X, Zhang G, Arendash GW. Protection against cognitive deficits and markers of neurodegeneration by long-term oral administration of melatonin in a transgenic model of Alzheimer disease. J Pineal Res. 2009;47:82-96.

123. Garcia-Alloza M, Borrelli LA, Hyman BT, Bacskai BJ. Antioxidants have a rapid and long-lasting effect on neuritic abnormalities in APPPS1 mice. Neurobiol Aging. 2010;31:2058-68

\section{Publisher's Note}

Springer Nature remains neutral with regard to jurisdictional claims in published maps and institutional affiliations.

Ready to submit your research? Choose BMC and benefit from:

- fast, convenient online submission

- thorough peer review by experienced researchers in your field

- rapid publication on acceptance

- support for research data, including large and complex data types

- gold Open Access which fosters wider collaboration and increased citations

- maximum visibility for your research: over $100 \mathrm{M}$ website views per year

At BMC, research is always in progress.

Learn more biomedcentral.com/submissions 